\title{
Monetary Policy, Hot Housing Markets And Leverage*
}

\author{
Christoph Ungerer ${ }^{\dagger}$
}

November 5, 2012

\begin{abstract}
Working Paper
Abstract

This paper presents a theory in which expansionary monetary policy causes a rise in leverage. Low mortgage rates encourage buyers to enter the housing market, raising the housing sales rate. Because lenders can resell seized foreclosure inventory at lower cost in such a hot housing market, ex-ante they feel comfortable financing a larger fraction of the house purchase. Consistent with this mechanism, this study documents empirically that the housing sales rate is highly sensitive to monetary policy. Calibrating a New Keynesian macroeconomic model augmented with credit-constrained consumers and with housing market search frictions, this housing liquidity channel of monetary policy contributes substantially to the effect of monetary policy on credit markets and the real economy. More generally, this framework suggests that measures to stimulate housing liquidity, including monetary policy alternatives such as home buyer tax credits, are key to stimulating access to credit.
\end{abstract}

Key Words: Monetary Policy; Housing Market; Credit Frictions; Search Frictions JEL Codes: E32; E44; E52; R21

*I am extremely grateful to Chris Pissarides, Ethan Ilzetzki, Wouter Den Haan and Dimitri Vayanos for many helpful discussions and their encouragement. I thank the UK Economic and Social Research Council (ESRC) and the Paul Woolley Centre for Capital Market Dysfunctionality for financial support.

${ }^{\dagger}$ Department of Economics, LSE, Houghton Street, London WC2A 2AE, UK, Tel: +44(0)2071075026, E-mail: c.t.ungerer@lse.ac.uk 
The conventional story of the housing channel of monetary policy transmission puts focus on housing transaction prices. Lower short-term policy rates feed through to mortgage rates, raising house prices to equilibrate demand and supply. As the transaction price of housing collateral rises, lenders allow credit-constrained consumers to borrow more. This stimulates aggregate demand and the macroeconomy. But this story neglects the substantial rise in the volume of housing sales following monetary policy easing. This study finds that a temporary $1 \%$ fall in the federal funds rate raises transaction prices by $3 \%$ on impact, while the monthly rate at which housing is sold rises by $20 \%$.

Does this housing sales rate response matter for macroeconomic monetary policy transmission? This paper explores one channel that suggests the answer is yes. Intuitively, lenders value property collateral primarily for its resale value in case of default. This liquidation value depends on both (i) costs associated with carrying the property from moment of foreclosure until a buyer is found and (ii) the eventual transaction price at which the house is resold to a new household. The response of the housing sales rate to expansionary monetary policy therefore matters, because it implies that housing liquidation values rise by more than recorded housing transaction prices when policy rates are lowered. This offers a theory for how loose monetary policy can cause a rise in the leverage ratios that lenders are willing to accept.

In a first step towards assessing the quantitative importance of this housing liquidity effect, this study backs out the monetary policy response of lender liquidation values from the empirical impulse responses of housing sales rate and transaction prices. Key to implementation of this exercise, net carrying costs on foreclosure inventory are approximated using estimates of property tax and maintenance costs. The housing liquidity effect more than doubles the impact response of lender liquidation values relative to housing transaction prices.

In a second step, this study evaluates the general equilibrium role of this housing liquidity effect for monetary policy transmission to the macroeconomy. Incorporating housing market search frictions into a Iacoviello (2005) New Keynesian macroeconomic model with credit-constrained entrepreneur-households, a framework emerges that formalizes the housing liquidity transmission channel in general equilibrium. Temporarily low interest rates make home purchase relatively attractive. As more home buyers scout the market of for-sale property, housing sellers can find counterparties more quickly. A temporary increase in the housing sales rate therefore arises as an endogenous response to expansionary monetary policy. In turn, higher housing sale rates increase housing liquidation values and allow lenders to threaten foreclosure more effectively. Ex-ante, this raises the willingness of lenders to provide credit. Borrowing margins relax, credit flows more easily and this stimulates aggregate activity. In a calibrated model, this housing 
liquidity effect contributes substantially to monetary policy transmission.

The importance of this housing liquidity transmission mechanism is not limited to monetary policy. It has also, for example, direct implications for our evaluation of the US home-buyer tax credit of 2009-2010. Consider a temporary subsidy to house purchases of $3 \%$ relative to trend house prices. Conventional macroeconomic analysis emphasizes that sellers may be able to exploit resulting greater housing demand by raising transaction prices. But this effect is bounded from above by a $3 \%$ house price rise (in which case the benefits of the subsidy are fully passed on to the seller). Taking search frictions into account, the overall impact on housing debt capacity may however be much larger. Because the subsidy encourages buyers to enter the market, it raises housing liquidity. Lender liquidation valuations of collateral may rise by more than transaction prices. Direct cyclical subsidization of home purchases may be a more effective substitute for monetary policy than conventional analysis suggests.

In establishing these results, this paper develops a new explanation for why expansionary monetary policy causes looser borrowing margins: lenders feel more comfortable lending because seized property collateral can be resold more easily in hot markets. Furthermore, the paper develops a tractable Dynamic Stochastic General Equilibrium model with both search frictions in the housing market as well as credit-constrained agents. This allows examination of the interaction between asset market search frictions and credit frictions in a medium-scale macroeconomic framework. Finally, this analysis offers a novel approach towards calibrating the housing market search frictions technology. In the labour markets literature, search friction technology parameters can be estimated directly, since both the number of workers searching for work (the unemployed) as well as job vacancies are recorded. In the housing market however, while measures of for-sale housing are available, the mass of searching house buyers is not. Instead this study proposes an indirect calibration approach using perturbations from monetary policy shocks.

This paper expands on the growing literature that explores the macroeconomic implications of credit frictions. In the spirit of Shleifer and Vishny (1992) and Kiyotaki and Moore (1997), agents have to offer collateral in order to access loans. Specifically, this paper builds on work by Iacoviello (2005) and Iacoviello and Neri (2010) in which consumers borrow against housing. However, while existing work puts emphasis on the feedback from asset prices to credit access (keeping borrowing margins fixed), this paper focusses on the amplifying role of time-varying borrowing margins. Emphasizing the substantial time-variation in housing transaction volumes and loan-to-value ratios, this study suggests that an exclusive focus on asset prices may substantially underestimate the response of overall asset debt capacity to monetary policy.

In this sense, this study complements other current work studying procyclical borrow- 
ing margins 11 Eisfeldt (2004) and Kurlat (2009) develop a theory of borrowing margins based on the greater severity of asymmetric information problems during downturns. Geanakoplos (2009) shows that disagreement between optimists and pessimists can cause leverage to rise during asset booms. ${ }^{2}$ Relative to this literature, this paper identifies the collateral sales rate as key contributing factor to borrowing margins in the housing market. Furthermore, this paper speaks directly to the popular notion that loose monetary policy causes loose credit conditions.

Finally, this paper is heavily indebted to the literature on markets with search frictions. Specifically, in terms of formalization and notation, this study borrows from the labour markets search frictions survey in Pissarides (2000). The idea that housing market search frictions are important for the evolution of house prices and transaction volume has been explored, among other contributions, in Wheaton (1990), Williams (1995), Krainer (2001), Albrecht et al. (2007), Novy-Marx (2009), Piazzesi and Schneider (2009) and Ngai and Tenreyro (2009). This paper applies these insights to study the interaction between search frictions in the housing market and access to mortgage finance $3^{3}$

Section 1 documents the response of the macroeconomy and the housing market to monetary policy shocks. Section 2 uses these impulse response functions in a simple accounting exercise to propose that housing liquidation values plausibly respond much more strongly than regular house transaction prices alone would suggest. To explore the macroeconomic significance of this housing liquidity effect, section 3 develops a New Keynesian general equilibrium model with borrowing-constrained households and search frictions in the housing market. Section 4 shows that this liquidity effect also magnifies the predicted potency of a more targeted stimulus to housing demand, such as a homebuyer tax credit. Section 5 offers concluding comments.

\footnotetext{
${ }^{1}$ The Costly-State-Verification models of Bernanke and Gertler (1989) and Bernanke, Gertler and Gilchrist (1999) also introduce time-varying leverage in a macroeconomic general equilibrium model, though this is not their focus. Because the setup implies a positive relation between credit spreads and leverage, their finding that spreads fall after expansionary monetary policy implies that leverage should fall. Linking their setup with the search frictions theory of asset liquidation values developed in this study appears a fruitful area for further research.

2 Simsek (2012) refines this work further, distinguishing between belief disagreement on the upside or downside of risk. In a related line of research, Brunnermeier and Pedersen (2009) and Adrian and Shin (2010) link borrowing margins to collateral asset return volatility.

${ }^{3}$ Parallel to the writing of this paper, Hedlund (2011) also proposes analysing the interaction between credit frictions and housing market search frictions. His paper puts focus on matching unconditional business cycle moments of the data, while this paper analyses how the interaction impacts the monetary policy response. This paper shows how to introduce this interaction in a New Keynesian general equilibrium model. Furthermore, this study disciplines the argument that search frictions matter using direct estimates of inventory holding costs: values for property tax and maintenance costs from the housing literature. This methodological insight is key to the quantitative exercises in this study. Also related, Milbradt and $\mathrm{He}(2012)$ study the interaction between liquidity and credit premium on corporate bonds in a search and matching market environment.
} 


\section{Dynamic Regressions: The Effect of Monetary Pol- icy on the Housing Market}

Documenting the reduced form dynamic response of the macroeconomy and the housing market to monetary policy shocks, this section establishes the key facts that frame and discipline the argument developed in this paper. To overcome endogeneity of monetary policy stance, this study adopts the methodology of Romer and Romer (2004) 4

Naive causal interpretation of the correlation between monetary policy stance and state of the real economy would conclude that expansionary monetary policy causes economic contractions. However, this neglects that the central bank policy rate responds endogenously to economic conditions, lowering rates in times of crisis precisely in order to counteract shocks from other sectors of the economy. To identify exogenous shocks to monetary policy, Romer and Romer (2004) therefore regress the historical intended federal fund rate on contemporaneous forecasts of the future macroeconomic state. They interpret the resulting estimated functional relationship as an estimate of the central bank policy response function. The historical deviation of actual federal funds rate from the policy rule (labelled $f_{t}$ ) therefore identifies movements in monetary policy that are not a response to macroeconomic fundamentals. Figure 1 plots the resulting monthly time series of exogenous US monetary policy shocks for the period 1969-1996.5 5

[Figure 1 about here.]

To analyse the dynamic impact of monetary policy shock $f_{t}$ on an economic variable of interest $x_{t}$, Romer and Romer (2004) propose the single-equation regression model 1.1. Monthly dummies $\left(D_{t}(k)\right.$ for dummy month $\left.k\right)$ are used as seasonal controls. Wherever not otherwise stated, the availability of the Romer and Romer (2004) shock series

\footnotetext{
${ }^{4}$ Appendix B lists data sources used in this empirical study. Appendix A explores robustness of the results developed. Crucially, it shows the key results developed in this section are qualitatively robust to using a recursive Vector-Autoregressions identification scheme along the lines of Christiano, Eichenbaum and Evans (2005) given the set of endogenous variables considered. The key benefit of using the Romer and Romer (2004) method in the main text is that the impulse response functions developed do not depend on the exact set of endogenous variables considered in the analysis.

5 Romer and Romer (2004) have generously made this data series available on their website http: //elsa.berkeley.edu/users/cromer/Shocks/RomerandRomerDataAppendix.xls at time of writing.

${ }^{6}$ What interpretation can we give to the monetary policy innovation $f_{t}$ ? Romer and Romer (2004) discuss six sources for the shock series: i. changes in central bank operating procedures (i.e. switch from focus on quantity measures to setting interest rates), ii. changes in the economic model used to reach policy decisions (i.e. speed of transmission from economic slack to inflation), iii. changes in tastes and goals of the monetary policy committee (ie periods of particular distaste for inflation), iv. political considerations (ie pursue expansionary monetary policy to secure renewed nomination of chair), v. special emphasis on non-standard targets during particular episodes (ie exchange rates in the mid-80s) and vi. idiosyncratic random elements in central bank decision making (ie mood swings).
} 
constrains the sample period considered in the regression.7

$$
\Delta \log \left(x_{t}\right)=a_{0}+\sum_{k=1}^{11} a_{k} D_{t}(k)+\sum_{l=1}^{L_{x}} b_{l} \Delta \log \left(x_{t-l}\right)+\sum_{l=1}^{L_{f}} c_{l} \Delta f_{t-l}+\epsilon_{t}
$$

Figure 2 plots the six monthly time series considered in this analysis: the federal funds rate, real output, the price level, real house prices, housing rents and the monthly housing sales rate (the monthly ratio of new houses sold to new houses for-sale) ${ }^{89}$ As crucial variable in the analysis of this study, note that the housing sales rate is highly cyclical (and seasonal). Furthermore, in any given month, the number of for-sale properties far exceeds the number of houses actually sold. Given an average sales rate of $17.7 \%$ (implying an average time-to-sale of 5.7 months), the time series reaches a minimum value of $7 \%$ and a maximum value of $33 \%$ 10:11: 12

[Figure 2 about here.]

What is the dynamic response of these macroeconomic and housing market aggregates to a one standard deviation Romer and Romer (2004) monetary policy shock? ${ }^{13}$

\footnotetext{
${ }^{7}$ Note specifically this means the results in this study, for better or for worse, do not cover the housing bubble of 2003-2007 and the subsequent credit crunch of 2006-2009.

${ }^{8}$ Note that the housing price series used (the Freddie Mac House Price Index) starts in 1975.

${ }^{9}$ Assuming (i) that for (most) households new and existing housing are broadly substitutable and (ii) that households prefer to search in less crowded markets, the new housing sales rate serves as useful proxy for the overall housing sales rate.

${ }^{10}$ The inverse of this sales rate is often used in the real estate industry as measure of months of supply available (the months it would take to sell current for-sale inventory given stable monthly sales and no new housing coming on the market). As in this paper, the measure reflects how many sellers are on the market relative to buyers (how crowded the market is). This measure is computed as part of the US Housing Census output for example.

${ }^{11}$ The procyclicality of housing transaction volumes has been previously documented in Stein (1995) for US data and Andrew and Meen (2003) for the UK economy. Stein (1995) proposes that downpayment effects can explain this patter. In recessions, house prices fall and household equity shrinks. Consequently, the sale of the current house would not cover downpayment for a mortgage on a new property and households cannot move. Genesove and Mayer (2001) propose that volume may dry up in times of falling house prices because households are averse to realizing losses on their housing investment. In contrast, this paper explains time-variation in housing transaction volumes based on the idea that the real estate market is characterized by search frictions (following Wheaton $(1990)$, Williams $(1995)$, Krainer $(2001)$, Albrecht et al. (2007), Novy-Marx (2009), Piazzesi and Schneider (2009) and Ngai and Tenreyro (2009)). The aim of this study is to explore the consequences of this housing liquidity response for household access to mortgages.

${ }^{12}$ Note also that this paper does not speak to housing market fluctuations at seasonal frequency. For work exploring this dimensionality of the data, see for example Ngai and Tenreyro (2009) and references therein.

${ }^{13}$ Following Romer and Romer (2004), confidence intervals are computed through Monte-Carlo simulations. 10000 regression coefficients and associated impulse responses are drawn from a multivariate normal distribution with mean at the point estimates and estimated variance-covariance matrix. The month $k$ standard error is then computed as the standard deviation across impulse response function values at month $k$.
} 
Figure 3 shows that the effective federal funds rate falls by 100 basis points within two months, recovers and then overshoots after two years (presumably reflecting the systematic response of the Federal Reserve to rising inflation). The macroeconomic response to monetary policy is substantial. Output rises to peak at $3 \%$ (relative to its trend value) after two years. The aggregate price level responds sluggishly at first, but inflation decidedly gains momentum as the economy reaches the two year mark. ${ }^{14}$ Turning to the housing market, as documented in for example Iacoviello (2005), house prices rise substantially after a fall in the federal funds rate (reaching a peak at $3 \%$ relative to steady state after 2 years). Rents, responding sluggishly to economic conditions, only decline in real terms as CPI inflation picks up 15

[Figure 3 about here.]

The crucial point of this section however is that the price response of housing pales in comparison with the response of the housing sales rate: the latter jumps by 20 percent immediately following the policy shock (from a long term average of $17.7 \%$ to $21.2 \%$ ). Only over time, as house prices pick up, does this increase in transaction volumes recede. 16

This finding motivates the key questions pursued in this paper: Why do housing transaction volumes pick up after monetary policy easing? Does the housing liquidity response contribute to macroeconomic transmission of monetary policy? Or is it simply a symptom that plays no active role in transmission? Is there a housing liquidity channel of monetary policy?

\section{A First Look at the Housing Liquidity Channel of Monetary Policy}

This section proposes one channel through which housing liquidity can play an active role in the overall monetary policy transmission process. Subsection 2.1 introduces the intuition behind this channel. Subsection 2.2 proposes a partial equilibrium accounting exercise to explore whether this mechanism can be quantitatively important. This paves the way for subsequent general equilibrium analysis.

\footnotetext{
${ }^{14}$ These impulse responses for the macroeconomic aggregates follow closely the results in Romer and Romer (2004). Specifically, relative to traditional recursive identification schemes, the real effect of monetary policy is stronger and the price level effect is more delayed.

${ }^{15}$ Note that a rental sector is not explicitly modelled in section 3 and it is not central to the mechanism of this study. Impulse response functions for rents are nonetheless included in this section to provide a more holistic picture of the housing market response to monetary policy.

${ }^{16}$ Previous studies that look at the response of housing market variables to monetary policy on the price and volume dimension confirm these empirical results (see Hort (2000) for Swedish data).
} 


\subsection{Intuition for the Channel}

At the heart of the traditional housing channel of monetary policy transmission lies the idea that central bank interest rates impact on the liquidation value lenders assign to housing collateral. With higher liquidation values, lenders support larger mortgages. High recovery rates make default less risky. Equally, higher liquidation values allow lenders to effectively threaten borrowers with seizure of collateral should households demand renegotiation of the mortgage. Either way, the resulting relaxation of borrowing constraints allows households to expand consumption and to fuel aggregate demand.

The housing liquidity channel developed in this paper shares with this traditional account its focus on housing liquidation values. Where the two stories differ however is on how liquidation values depend on current housing market conditions. In the baseline credit frictions literature centred on Shleifer and Vishny (1992), Kiyotaki and Moore (1997) and Iacoviello (2005), the assumption of Walrasian asset markets implies that banks can instantly resell foreclosed housing at current market price (allowing for one-off costs associated with the transaction). By implication, the monetary policy response of housing liquidation values is directly tied to the extent to which central banks move current real estate transaction prices. In contrast, this paper captures the fact that banks take time to resell foreclosed property on the market. Given regular house transaction prices, housing liquidation values are higher in a hot housing market in which houses can be sold quickly, since the seller faces lower expected holding costs (such as maintenance and tax on the vacant property). In this setup, the response of vacant housing liquidation values to monetary policy depends both on the monetary policy response of house prices and the housing sales rate. ${ }^{17}$

Taking into account this link between liquidation values and housing time-to-sale, a natural mechanism emerges through which the housing market liquidity response from section 1 may play an active role in monetary policy transmission. As expansionary monetary policy lowers mortgage rates and attracts more buyers into the housing market, time-to-sale for foreclosed properties falls. This means that the liquidation value banks assign to housing collateral rises by more than transaction prices. The resulting excess sensitivity of housing credit access (relative to housing transaction price) gives rise to a housing liquidity channel of monetary policy.

\footnotetext{
${ }^{17}$ On foreclosure, properties are generally subject to an auction. Only if the auction fails, does the property become part of the lender foreclosure inventory. Because in the foreclosure dataset of Campbell, Giglio and Pathak (2009) only $18 \%$ of foreclosures are sold at that stage, this paper abstracts from the auction procedure and assumes housing directly enters the lender housing inventory to be sold on the regular housing market.
} 


\subsection{An Initial Quantitative Exploration}

This subsection uses a simple accounting exercise to offer an initial quantitative exploration of this housing liquity channel. Denote the liquidation value banks assign to a vacant house in their foreclosure inventory by $q_{v, t}$. Denote the per-period net holding costs the bank pays on vacant property, such as maintenance costs and property tax, by $c_{h}$. Given a new occupier for the property is found, the house is sold at market price $q_{m, t}$ and the seller pays a one-off proportional fixed sales cost $F_{s}$ (reflecting for example real estate agent fees). Denoting the probability that a seller finds a willing buyer in period $t$ with $P_{s, t}$ and denoting the seller stochastic discount factor with $Q_{t}$, the housing liquidation value is given by present value equation 2.1 .

$$
q_{v, t}=E_{t}\left(Q_{t+1}\left(-c_{h}+P_{s, t+1} q_{m, t+1}\left(1-F_{s}\right)+\left(1-P_{s, t+1}\right) q_{v, t+1}\right)\right.
$$

To make equation 2.1 operational, this section requires an expression that identifies the seller discount factor $Q_{t+1}$ empirically. The study therefore makes the assumption that banks price the risk-free asset with return $R_{f, t}$, yielding equilibrium expression 2.2 .

$$
1=R_{f, t} E_{t}\left(Q_{t+1}\right)
$$

Equations 2.1 and 2.2 represent basic accounting equations that will hold in a large class of general equilibrium settings. For example, they will be derived as outcomes of optimizing behaviour in the macroeconomic model of section 3 . Key however is that these two expressions in themselves impose sufficient structure to infer from the impulse responses in section 1 how housing liquidation values respond to monetary policy.

Using first order approximations around the non-stochastic steady state, iterating 2.1 forward, imposing a no-bubble condition and using 2.2 to substitute out the discount factor, yields expression 2.3 ${ }^{18}$ This equation is key to the quantitative exercise in this section. Given a calibration for $\rho_{1}, \rho_{2}$ and $\rho_{3}$, it backs out the liquidation value banks assign to housing collateral given the expected path of the risk-free rate, the housing sales rate and housing transaction prices (computed in section 1).

At this point, it is useful to note two features of this setup. First, note that the liquidation value can be interpreted as the price at which housing can be sold instantly on the market (to any speculator). Any intermediary will be willing to buy the house at liquidation value, since the implied fire-sale discount relative to regular transaction price compensates for expected holding costs until the house can be resold to a buyer

\footnotetext{
${ }^{18}$ Terms with star superscript denote steady state values and terms with hat accent denote (log) deviations from steady state. Appendix E derives expression 2.3 formally.
} 
household ${ }^{19}$ Second, the sensitivity of housing liquidation values to the housing sales rate depends on the difference between this steady state fire-sale discount $1-\left(q_{v}^{*} / q_{m}^{*}\right)$ and the one-off cost of making the sale $F_{s}$ (see $\rho_{1}$ ). Approximately, this difference represents how much of the steady state fire-sale discount is explained by expected holding costs. If expected holding costs are important, then the fire-sale discount also becomes more sensitive to fluctuations in the sales rate around steady state.

$$
\begin{aligned}
& \hat{q}_{v, t}= \underbrace{-\sum_{j=0}^{\infty} \rho_{3}^{j} E_{t}\left(\hat{r}_{f, t+1+j}\right)}_{\text {Discount factor component }}+\underbrace{\rho_{1} \sum_{j=0}^{\infty} \rho_{3}^{j} E_{t}\left(\hat{p}_{s, t+1+j}\right)}_{\text {Sales rate component }}+\underbrace{\rho_{2} \sum_{j=0}^{\infty} \rho_{3}^{j} E_{t}\left(\hat{q}_{m, t+1+j}\right)}_{\text {Price component }} \\
& \text { where } \rho_{1}=\frac{Q^{*}\left(\left(1-F_{s}\right)-\left(q_{v}^{*} / q_{m}^{*}\right)\right) P_{s}^{*}}{\left(q_{v}^{*} / q_{m}^{*}\right)} \\
& \rho_{2}=\frac{Q^{*} P_{s}^{*}\left(1-F_{s}\right)}{\left(q_{v}^{*} / q_{m}^{*}\right)} \\
& \rho_{3}=Q^{*}\left(1-P_{s}^{*}\right)
\end{aligned}
$$

To calibrate expression 2.3 at monthly frequency, set the yearly steady state riskfree rate to $4 \%$. To gauge the size of the steady state fire-sale discount in the housing market, this study uses evidence from existing empirical studies. Mayer (1998) finds that housing sales at auctions in the 1980s (generally associated with foreclosure events) sell at discounts of up to $9 \%$ in Los Angeles (boom market) and 9-21\% in Dallas (oil bust). In a study of the Massachusetts housing market, Campbell, Giglio and Pathak (2009) estimate foreclosure-related price discounts of $27 \%$ of house value 20 Taking orientation around these numbers, this paper assumes an average fire-sale discount of $15 \%$ as baseline scenario 21

It is generally difficult to pin down what fraction of the fire-sale discount on housing is explained by expected holding costs during time-to-sale and what fraction is explained

\footnotetext{
${ }^{19}$ In other words, the fire-sale discount reflects compensation for delegation of the search task to another agent.

${ }^{20}$ The Campbell, Giglio and Pathak (2009) foreclosure discount is an imperfect proxy for the fire-sale discount discussed in this paper, since they consider all sales of foreclosed housing (irrespective of whether they are instant) relative to regular transaction prices.

${ }^{21}$ This calibration has a second convenient interpretation. In the general equilibrium model of section 3 , it will also represent the loan-to-value ratio on mortgages of credit-constrained households. A loan-tovalue ratio of $85 \%$ for credit constrained households conforms with the prior set in Iacoviello and Neri (2010) for example.
} 
by the one-off seller transaction costs once a buyer household is found ${ }^{22}{ }^{23}$ At the same time, as the expression for $\rho_{1}$ demonstrates, exactly this calibration decision is crucial in determining how sensitive housing liquidation values are to the housing sales rate. This study therefore takes a conservative baseline approach in the main text. It formulates a lower bound on the size of expected holding costs and shows that, even given this conservative choice, the housing liquidity channel is a potent factor in the valuation of vacant for-sale housing. Specifically, as in Poterba (1991), this study assumes yearly holding costs of a vacant property equal yearly property tax and maintenance costs at $2 \%$ and $3.9 \%$ of house price respectively $\left(c_{h}=m+\tau\right)$. Through expression 2.1, this implies one-off seller transaction costs of around $10 \%$ of steady state regular house price.

[Figure 4 about here.]

Under this conservative baseline parameterization, the impulse response function for the housing liquidation value can be backed out by feeding the section 1 reduced-form responses of the sales rate, transaction prices and the risk-free rate into expression 2.3 . This results in figure 4 and illustrates the main point of the paper: housing liquidation values plausibly respond much more strongly to monetary policy than regular transaction prices alone would suggest.24 Figure 5 shows that this overshooting can be traced back in large part to the strong sales rate response of the housing market.25 Only after transaction volumes return to steady state in year 3 (post policy shock) does the response of liquidation values reflect more closely the behaviour of contemporaneous transaction prices.

[Figure 5 about here.]

Three arguments suggest that, in practice, figure 5 likely represents a lower bound on the true sensitivity of liquidation values to fluctuations in the housing sales rate. First, the $10 \%$ one-off seller transactions cost implied by the calibration appear high.

\footnotetext{
${ }^{22}$ This problem is made even more difficult in that, strictly speaking, the one-off transaction costs in this accounting framework represent only those transaction costs that are incurred if the house is sold to a new household in a regular sale - over and on top one-off transaction costs that would be incurred irrespective of whether the house is sold to a household or to a speculator.

${ }^{23}$ This problem is at the heart of the empirical study by Campbell, Giglio and Pathak (2009) for example.

${ }^{24}$ To make equation 2.3 operational, the summation is truncated at 60 months. Results are insensitive to raising the number of months considered.

${ }^{25}$ The discount factor and future transaction price components reinforce this effect. First, temporarily lower interest rates lower the opportunity cost of funds tied up in foreclosure inventory. Second, on impact, expansionary monetary policy feeds expectations of future house price appreciation (see the impulse response of house prices in section 11. Both these additional components raise housing liquidation values relative to current housing transaction prices (reinforcing the effect of a temporarily high sales rate).
} 
Suppose, as is standard in the US, that housing sellers pay real estate agents a fee of $3 \%$ of the house price ${ }^{26}$ Assume an additional $1 \%$ in additional legal fees associated with the sales procedure. This leaves another $6 \%$ of the estimated one-off seller transaction cost unexplained. These additional costs could be rationalized by the cost of housing repairs and a general pre-sale face-lift, but more likely they suggest that the calibration underestimates expected holding costs during time-to-sale. Second, note that, in fact, Poterba (1991) suggests that ownership risk substantially drives up the holding costs of property. Effectively, owning a vacant house creates exposure to future house price fluctuations. Adding a yearly $4 \%$ risk premium to property holding costs, Poterba (1991) therefore estimates that overall yearly holding costs for housing are about 10\% (relative to the $6 \%$ parameterization used in the conservative baseline scenario of this paper) ${ }^{27}$ Finally, notice that some empirical studies offer (rough) points of orientation regarding the trade-off between time-to-sale and sales price in the housing market. Genesove and Mayer (2001) suggest that homeowners with larger mortgages relative to housing value prefer to sell housing at a higher price. Specifically, 100\% loan-to-value sellers keep houses 15 percent longer on the market and sell at 4\% higher price (relative to an $80 \%$ loan-to-value seller). Levitt and Syverson (2008) find that realtors keep their own houses 10 percent longer on the market and end up selling at a $4 \%$ higher price than when they sell someone else's house. To explain this, Levitt and Syverson (2008) point to fixed real estate agent fees (proportional to sales price). This pricing structure means that agents have an incentive to sell other people's houses quickly (they bear all the search costs associated with keeping the property on the market for longer, while reaping only a faction of the eventual gain in sales price). Either of these studies suggests that house prices are significantly more sensitive to time-to-sale than the model in this paper suggests.

Overall, this quantitative exercise shows that the empirical housing liquidity response to monetary policy is indeed strong enough to substantially raise housing liquidation values relative to observed transaction prices. However, it does not offer a story for why the housing market responds to central bank action through both house price and sales

\footnotetext{
${ }^{26}$ See Hsieh and Moretti (2003) and Levitt and Syverson (2008) that document this pricing practice and discuss its implications.

${ }^{27}$ Though adding a risk premium to the baseline property holding cost used in this study would strengthen the estimated magnitude of the housing liquidity channel (and therefore the case of this paper), this study refrains from its inclusion in the conservative baseline calibration for two reasons. First, the size of this risk premium is highly uncertain. By showing that the housing liquidity effect is important even if one believes that the risk premium is negligible, this paper highlights that whatever one assumes about the risk premium is not crucial to the quantitative argument in this paper. Second, note that this paper develops solutions using first-order approximation methods (as is common in the macroeconomic business cycle literature). In these approximations, risk considerations generally do not enter (they start to matter moving to second order approximations and higher). Ignoring the risk premium therefore ensures consistency of the calibration with the solution method used.
} 
rate margin. It does not explicitly spell out how this collateral liquidity effect translates into expanding consumer credit and output growth. It does not estimate the contribution of the housing liquidity channel of monetary policy to the overall macroeconomic effect of central bank action. Section 3 develops a structural macroeconomic model that attempts to address these issues.

\section{A Macroeconomic General Equilibrium Model}

This section introduces housing market search frictions into the Dynamic Stochastic General Equilibrium model with credit-constrained consumers developed in Iacoviello (2005) and Iacoviello and Neri (2010). In this setup, the housing sales rate naturally manifests itself as a determinant of housing fire-sale discounts and of household borrowing margins, yielding a housing liquidity channel of monetary policy transmission to the real economy.

The model is calibrated to match the monetary policy impulse response functions of section 1. A counterfactual simulation then allows to gauge the quantitative significance of the liquidity effect for monetary policy transmission to mortgage lending and the real economy. If lenders were forced to maintain steady-state loan-to-value ratios on new mortgages (in effect re-establishing the traditional link between housing debt capacity and house price of the Walrasian setup), the simulations predict that the cumulative impact of a $1 \%$ temporary fall in the policy rate on output would fall from $5 \%$ to $3 \%$.

\subsection{Model Structure}

The economy consists of four agent types. Patient (p) consumer households consume, work, occupy housing and trade in a range of financial assets. Impatient (ip) entrepreneur households also consume, work, occupy housing and trade in a range of financial assets. However, in addition, they operate wholesale firms on their properties to produce intermediate goods. In equilibrium, impatient households will demand to borrow from the patient, creating a role for credit markets. Retail firms transform intermediates production into final goods that are sold to consumers under monopolistic competition with Calvo-style price adjustment rigidities. Finally, a central bank regulates nominal interest rates according to a Taylor-type monetary policy rule.

As shown in figure 6, each period $t$ consists of four phases. In the first phase, aggregate shock innovations to the economy are observed. In the second phase, a fraction of occupied housing becomes unsuitable for the current occupiers (it becomes effectively vacant). The household may have to move town because of a new job opportunity. A growing family may require a house with more room for their children. A retired couple may wish to 
trade down into a smaller housing unit with wheelchair access. In the third phase, the housing, goods, labour, equity and debt markets open. Key is that households engage in a costly and time intensive search process to find a suitable new home. In the fourth phase, debtor households can make an offer to renegotiate debt (in the spirit of Hart and Moore (1994) and Kiyotaki and Moore (1997)). The creditor has the choice of accepting or rejecting the proposal. This renegotiation threat makes the collateral constraint of debt contracts relevant in equilibrium.

[Figure 6 about here.]

\subsubsection{Households}

Type $i$ households value consumption $c_{t}^{i}$ and fit-for-occupation (matched) housing $h_{t}^{i}$. They experience disutility from providing labour effort $l_{t}^{i}$. Assuming that within-type households insure each other against idiosyncratic shocks through informal and formal financial contracts, all within-type households face identical decision problems. For analytical tractability, the setup can therefore be thought of as consisting of one patient and one impatient representative household ${ }^{28}$ As in Iacoviello (2005) and Iacoviello and Neri (2010), this paper assumes an expected utility objective function 3.1 for type $i$ households with log utility in consumption and housing as well as general CRRA utility in leisure ${ }^{29}$ As key distinguishing feature between the two consumer types, patient households put greater weight on future felicity $\left(\beta^{p}>\beta^{i p}\right)$. In equilibrium, this will generate existence of a debt market in which patient households lend their savings to impatient households.

$$
\sum_{s=0}\left(\beta^{i}\right)^{t+s} E_{t}\left(\ln \left(c_{t+s}^{i}\right)+j \ln \left(h_{t+s}^{i}\right)-\chi \frac{\left(l_{t+s}^{i}\right)^{1+\eta}}{1+\eta}\right)
$$

A fraction $z$ of occupied housing becomes unfit for its current residents in phase 2 of period $t$. For simplicity, assume that owning housing that is unfit yields no utility benefits to its current owner. In this sense, unfit housing becomes effectively vacant.

\footnotetext{
${ }^{28}$ The big family assumption is clearly a convenient stylized modelling device (see its explicit use in Merz (1995) and Andolfatto (1996)). However, the notion has roots in reality. Assume a grandfather is bound to a wheelchair and can therefore not climb the stairs of his home. The daughter may have to drive to the grandfather's house after work every day to help him with the household. An office worker may find a new job in a distant city. To avoid the long commute, he may ask friends to stay in their guest room weekdays until his old house can be sold and he can himself settle closer to work. In utility terms, the cost of mismatched housing may well be spread across the extended network of a household.

${ }^{29}$ The log functional restrictions for consumption and housing ensure a stable relation between housing expenditures and consumption even in periods of prolonged house price deviations from steady state (see Davis and Heathcote (2005) and Fisher (2007)).
} 
Given new acquisitions of matched housing $a_{m, t}^{i}$, equation 3.3 denotes the evolution of occupied housing for households of type $i$.

$$
h_{t}^{i}=(1-z) h_{t-1}^{i}+a_{m, t}^{i}
$$

To acquire new occupied housing, households search with effort $e_{t}^{i} \geq 0$. Denoting by $P_{b, t}$ the probability of finding appropriate housing (per unit of search effort), new acquisitions of matched housing are described by equation 3.4 .

$$
a_{m, t}^{i}=P_{b, t} e_{t}^{i}
$$

Housing that becomes vacant is offered for sale to households searching for new homes (with per-period probability of sale $P_{s, t}$ ). If an appropriate buyer household is found, the transaction takes place at regular market price $q_{m, t}$. Once the search market closes, a vacant housing spot market opens in which vacant lots can be sold instantly to speculators at fire-sale price $q_{v, t}$ (denote by $a_{v, t}^{i}$ net acquisitions of vacant housing in the spot market). These instant sales effectively delegate search for new housing end-users to other households acting as intermediary. Equation 3.5 denotes the evolution of vacant housing held by type $i$ households at the end of period $t 30$

$$
v_{t}^{i}=\left(1-P_{s, t}\right)\left(v_{t-1}^{i}+z h_{t-1}^{i}\right)+a_{v, t}^{i}
$$

Transactions on the housing market are costly. In search market transactions that lead to occupation, buyers and sellers incur proportional one-off transaction costs $F_{b}$ and $F_{s}$. Buyers pay consumption cost $\kappa_{b}$ per unit of search effort devoted to finding new housing fit for occupation ${ }^{31}$ At the start of period $t$, households pay maintenance $m$ and property $\operatorname{tax} \tau$ on all housing held (vacant as well as occupied).

Equity in retail firms held $o_{t}^{i}$ (normalized to net supply measure 1) trades on a spot market at price $q_{o, t}$. Given retail firm dividends $\Pi_{r, t}$, equity holdings yield $\Pi_{r, t} o_{t-1}^{i}$ in period $t$. Denote by $\Pi_{w, t}^{i}$ profits from wholesale production activity by consumer type

\footnotetext{
${ }^{30}$ The existence of a spot market for vacant housing has two aims. First, conceptually, it offers households the option to sell quickly to a speculator (at a liquidation discount) or to engage in lengthy and costly search for a regular house buyer (and then sell at a higher regular price). In a stylized way, the framework therefore features a trade-off between speed of sale and sale price. In this sense, monetary policy affects the steepness of this trade-off. Second, technically, the vacant housing spot market ensures that vacant housing is priced by those households that put highest value on holding it (the patient households in equilibrium). This will simplify the bargaining game, since all sellers put the same value on owning vacant housing at the end of every period.

${ }^{31} \mathrm{As}$ in section 2 assume sellers face no per-period direct intermediation costs (intermediation costs instead are paid one-off as part of $F_{s}$ ). Notice this assumption is not crucial for results. In fact, raising the cost of holding vacant housing inventory would increase the relevance of the housing liquidity channel further.
} 
( $\Pi_{w, t}^{p}=0$ trivially, since only the impatient consumer is assumed to act as entrepreneur) taxed at rate $\tau_{w}$. Denote government transfers to households by $T_{t}^{i}$. Denoting the nominal return on debt by $R_{t-1}$ and denoting inflation by $\pi_{t}=p_{t} / p_{t-1}$, the real debt yield is $R_{t-1} / \pi_{t}$. Given wage $w_{t}^{i}$, equation 3.6 denotes the consumer budget constraint.

$$
\begin{aligned}
& c_{t}^{i}+\frac{R_{t-1} b_{t-1}^{i}}{\pi_{t}}+q_{o, t} \Delta o_{t}^{i}-\left(w_{t}^{i} l_{t}^{i}+b_{t}^{i}+o_{t-1}^{i} \Pi_{r, t}+\left(1-\tau_{w}\right) \Pi_{w, t}^{i}+T_{t}^{i}\right) \\
= & \underbrace{q_{m, t}\left(1-F_{s}\right) P_{s, t}\left(v_{t-1}^{i}+z h_{t-1}^{i}\right)}_{\text {Revenue from housing sales to new occupiers }}-\underbrace{\left(q_{v, t} a_{v, t}^{i}+q_{m, t}\left(1+F_{b}\right) a_{m, t}^{i}\right)}_{\text {Cost of property purchases }}
\end{aligned}
$$

$$
-\underbrace{\kappa_{b} e_{t}^{i}}_{\text {Cost of search effort }} \quad-\underbrace{\left((m+\tau)\left(h_{t-1}^{i}+v_{t-1}^{i}\right)\right)}_{\text {Cost of tax and maintenance on housing }}
$$

Finally and crucially, the threat of debt renegotiation in phase four of period $t$ imposes a borrowing constraint (as in Kiyotaki and Moore (1997) and Iacoviello (2005)). Effectively, borrowers have the option to repudiate the debt contract (in the spirit of Hart and Moore (1994)) in phase four of period $t$. In that case the lender takes control of the housing collateral underlying the contract. The borrower makes a take-it-or-leave-it alternative loan repayment offer to keep the house. The lender can either accept this alternative offer or he can move the house into his foreclosure inventory.

To prevent renegotiation, lenders ex-ante must keep the loan small enough relative to the liquidation value they assign to collateral. They can then credibly commit to not accepting renegotiation offers. Equation 3.7 denotes the relevant condition.

$$
E_{t}\left(Q_{t+1}^{i^{\prime}} \frac{R_{t}}{\pi_{t+1}}\right) b_{t}^{i} \leq q_{v, t} h_{t}^{i}
$$

\subsubsection{Search And Matching In The Housing Market}

The search market for fit-for-occupation housing uses the labour market formalization summarized in Pissarides (2000). Assume a Cobb-Douglas matching function $M_{t}$ that determines the mass of matches between buyers and sellers as function of aggregate buyer search effort $e_{t}$ and vacant housing (the old stock $v_{t-1}$ carried over from last period and newly vacated housing $\left.z \sum_{i} h_{t-1}^{i}\right)$.

$$
M_{t}=e_{t}^{1-\gamma}\left(v_{t-1}+z \sum_{i} h_{t-1}^{i}\right)^{\gamma}
$$

Here aggregate search effort and vacant properties are straightforwardly defined from 
their type-specific equivalents:

$$
\begin{gathered}
e_{t}=e_{t}^{p}+e_{t}^{i p} \\
v_{t-1}=v_{t-1}^{p}+v_{t-1}^{i p}
\end{gathered}
$$

Defining market tightness $\theta_{t}$ as the ratio of search effort over vacant housing, this yields closed-form solutions for the matching probabilities of buyers and sellers.

$$
\begin{aligned}
& P_{b, t}=\frac{M_{t}}{e_{t}}=\theta_{t}^{-\gamma} \\
& P_{s, t}=\frac{M_{t}}{v_{t-1}}=\theta_{t}^{1-\gamma}
\end{aligned}
$$

How is the average transaction price $q_{m, t}$ determined once a household finds a vacant house it is willing to occupy? From section 1, it appears that house prices are sluggish. The model therefore assumes that house prices have a backward-looking component (encompassing flexible price Nash-bargaining as a special case). Specifically, assume that the average house transaction price in period $t$ is determined as weighted average of the average transaction price in the preceding period and the current price outcome from Nash bargaining $\left(q_{m, t}^{N}\right)$. In calibration of the model, the sluggishness parameters $s$ of this pricing equation is set to match the impulse response function of the housing market to monetary policy (with $s=1$ yielding fully flexible Nash-bargained house prices) 32

$$
q_{m, t}=s q_{m, t}^{N}+(1-s) q_{m, t-1}
$$

In the Nash bargaining solution to the search market house price $q_{m, t}^{N}$, denote the buyer and seller surplus from a transaction as the gain from making the transaction happen against the outside option of breaking off negotiations (without a new counterparty search being possible in period $t$ ). Since sellers can sell on the vacant housing spot market if they cannot sell on the search market, the outside option of sellers (of either consumer type) equals the vacant housing liquidation price $q_{v, t}$ in equilibrium. Denoting by $\omega$ the share of

\footnotetext{
${ }^{32} \mathrm{~A}$ simple story justifying pricing rule 3.11 goes as follows. Assume that the economy consists of a large number of regions (and, implicitly, that search effort cannot be directed at specific regions). In a given region, the transaction price is determined with reference to the previous period transaction price with probability $1-s$. With probability $s$, the transaction price is determined by the outcome $q_{m, t}^{N}$ of Nash bargaining between buyer and seller (defined further below). It follows that a region features the Nash bargaining price of $k$ periods ago with probability $(1-s)^{k} s$. If transactions occur whenever buyers find an appropriate vacant property, it follows that the average transaction price is given as weighted average of past Nash bargaining prices: $q_{m, t}=s q_{m, t}^{N}+(1-s) s q_{m, t-1}^{N}+s(1-s)^{2} q_{m, t-2}^{N}+\ldots$. Writing this expression recursively yields equation 3.11 (as a natural analogue to Calvo pricing in firm price-setting).
} 
the total transaction surplus accruing to the seller (the bargaining weight) and by $V_{t}^{f}$ the fundamental valuation that households assign to fit-for-occupation housing, this implies a unique per-period Nash bargained price determined by equation 3.12 (irrespective of which consumer type is buyer or seller in a specific negotiation) ${ }^{33}$

$$
q_{m, t}^{N}\left(1-F_{s}\right)-q_{v, t}=\omega\left(V_{t}^{f}-q_{v, t}-\left(F_{s}+F_{b}\right) q_{m, t}^{N}\right)
$$

\subsubsection{Firms, Policy \& The Shock Process}

Impatient households use their occupied property, together with hired labour, to produce intermediate inputs. Output is sold to retailers in a perfectly competitive market at price $p_{t}$. Denoting by $x_{t}$ the retailer mark-up on prices, equation 3.13 denotes the problem of the wholesale firm. The parameter $\alpha$ sets the equilibrium fraction of income going to labour. Equally, $\mu$ determines the fraction of labour income going to patient workers ${ }^{34}$

$$
\operatorname{Max} \frac{1}{x_{t}} A\left(h_{t}^{i p}\right)^{\alpha}\left(\left(l_{t}^{p}\right)^{\mu}\left(l_{t}^{i p}\right)^{1-\mu}\right)^{1-\alpha}-\sum_{i} w_{t}^{i} l_{t}^{i}
$$

Following the New Keynesian literature, retail firms differentiate output by type $j$ and set prices $p_{t}(j)$ in a monopolistically competitive environment subject to Calvo-pricing (a fraction $\vartheta$ of firms can adjust prices in period $t$ ). Consumers aggregate output subject to a Dixit-Stiglitz technology. The optimisation problem for those retail firms that can adjust prices is therefore given by expression 3.14$]^{35}$ Profits from market power are rebated to the consumer through lump-sum per period dividends $\Pi_{r, t}$.

$$
\begin{gathered}
\operatorname{Max}_{p_{t}(j)} \sum_{s=0}\left(\vartheta_{f} \beta^{p}\right)^{s} \frac{c_{t}^{p}}{c_{t+s}^{p}} \frac{p_{t}}{p_{t+s}}\left(p_{t}(j)-p_{t+s}\right) y_{t+s}(j) \\
\text { s.t. } y_{t+s}(j)=\left(\frac{p_{t+s}}{p_{t}(j)}\right)^{\frac{\lambda_{f}}{\lambda_{f}-1}} y_{t+s}
\end{gathered}
$$

Following standard derivation (see Gali (2008)), this setup yields a forward-looking

\footnotetext{
${ }^{33}$ In the neighbourhood of the steady state, fundamental valuation of a matched property will be equalized across household types (see below). In introducing notation in this section, I anticipate this result.

${ }^{34}$ In equilibrium, competitive input markets imply wholesale profits $\Pi_{w, t}^{i p}=$ $\left(\alpha / x_{t}\right)\left(A\left(h_{t}^{i p}\right)^{\alpha}\left(l_{t}^{p}\right)^{(1-\alpha) \mu}\left(l_{t}^{n p}\right)^{(1-\alpha)(1-\mu)} / h_{t}^{i p}\right)$. By assumption, $\Pi_{w, t}^{p}=0$ since patient households are assumed not to be entrepreneurs. Notice, as special case of this framework, $\alpha=0$ is observationally equivalent to a model in which patient and impatient are only households, wholesale firms make no profits and use only labour in production.

${ }^{35}$ The assumption that firms use the discounting factor of the patient consumer to evaluate future profits is subsequently validated, as in the neighbourhood of the steady state only patient households will hold firm equity.
} 
Phillips curve. Current inflation depends on expectations of future inflation and current mark-up of retailers over wholesale producers $\left(\hat{X}_{t}\right.$ in deviation from steady state). Here we define $\left.\nu=(1-\vartheta)\left(1-\beta^{p} \vartheta\right) / \vartheta\right)$.

$$
\pi_{t}=\beta^{p} E_{t}\left(\pi_{t+1}\right)-\nu \hat{X}_{t}
$$

The central bank sets interest rates according to a Taylor-type interest rate rule for monetary policy. Effectively, the central bank lowers the interest rate in response to widening of the output gap as well as rising inflation. Implicitly, the model assumes zero steady state inflation.

$$
R_{t}=R^{*} \pi_{t}^{1+r_{\pi}}\left(\frac{Y_{t}}{Y^{*}}\right)^{r_{Y}} m_{r, t}
$$

The baseline setup explores AR(1) monetary policy shocks to this Taylor rule of form:

$$
\log \left(m_{r, t}\right)=\rho_{m r} \log \left(m_{r, t-1}\right)+\epsilon_{m r, t}
$$

Finally, assume that government redistributes tax on wholesale firm profits to patient consumer households. This is a technical assumption to ensure that patient households remain economically significant in steady state debt markets (despite the asymmetric assumption that only impatient households derive income from entrepreneurial activity). ${ }^{36}$

$$
T_{t}^{p}=\tau\left(\Pi_{t}^{w}\right)
$$

\subsubsection{Equilibrium}

To recapitulate, it is useful to define formally an equilibrium in this environment. An equilibrium is an allocation of prices $\left(R_{t}, r_{t}, w_{t}^{i}, q_{m, t}, q_{v, t}, p_{t}, q_{o, t}\right)$ and quantities $\left(a_{m, t}^{i}\right.$, $\left.a_{v, t}^{i}, c_{t}^{i}, h_{t}^{i}, v_{t}^{i}, e_{t}^{i}, l_{t}^{i}, o_{t}^{i}, b_{t}^{i}, y_{t}(j)\right)$ such that households maximimize utility, firms maximize profits, the search and matching market for foreclosed housing follow the dynamics set out in subsection 3.1.2, monetary policy follows the prescribed Taylor rule and all remaining markets clear given any history of shock realizations. Figure 7 presents a graphical overview of the markets in this economy. Appendix $\mathrm{C}$ derives the first order conditions associated with the equilibrium.

[Figure 7 about here.]

\footnotetext{
${ }^{36}$ This transfer policy implies trivially $T_{t}^{i p}=0$.
} 


\subsection{Analytical Implications}

The main features of this general equilibrium model can be represented analytically. First, the assumed joint existence of a search market in which housing can be sold to new occupants as well as a spot market in which vacant housing can be sold to speculators (effectively delegating search for new occupants) ensures that the steady state (and dynamics around the steady state) can be characterized transparently. Second, because low interest rates make home ownership more attractive, expansionary monetary policy raises the number of buyers searching for housing and therefore the rate at which vacant houses are sold. Third, higher housing sale rates raise the liquidation value of a foreclosed house (relative to regular house price), making the foreclosure threat of lenders more effective and therefore making banks ex-ante more willing to offer households larger loans. This suggests the existence of a housing liquidity channel of monetary policy transmission to the real economy. Fourth, under a flexible Nash-bargaining of house prices, a low housing sales rate allows buyers to drive down house prices, making buyer entry into the housing market more attractive and raising the housing sales rate. To get quantitatively large movements in housing liquidity in response to external shocks, some sluggishness in house prices is needed 37 This subsection discusses each of these four model implications in turn.

\subsubsection{Steady State}

Since the remainder of the paper will be concerned with local perturbations around the steady state, it is useful to start by specifying the salient properties of this steady state through a series of statements (appendix D develops analytical proofs).

Implication 3.1. In any non-stochastic steady state, the impatient consumer is borrowingconstrained and the patient consumer is not

A simple contradiction argument offers an intuitive interpretation. Conjecture a steady state in which the impatient consumer is not borrowing-constrained. For the bonds market to clear, steady state bond interest rates must be such that the impatient consumer is indifferent between borrowing and saving. But then the patient consumer must have unbounded demand for saving. The bond market cannot be in equilibrium.

This explains why the assumed heterogeneity in consumer discount rates ensures an operational (non-trivial) steady state credit market in the model. Moreover, for small

\footnotetext{
${ }^{37}$ Alternatively, one could limit free buyer entry into the housing market or modify the assumption of a Cobb Douglas matching function. However, given the empirical dynamic response of house prices in section 1 suggests sluggishness in price setting, breaking the Nash bargaining assumption appears a natural starting point.
} 
perturbations of the model economy, it follows that the response of impatient households is limited by a binding credit constraint (while the patient consumer is unconstrained).

Implication 3.2. In any non-stochastic steady state:

- Patient and impatient households are committing search effort to finding new housing for occupation $\left(e_{t}^{i}>0 \forall i=p, i p\right)$

- Patient and impatient households assign the same fundamental value to occupied housing $\left(V_{f, t}^{p}=V_{f, t}^{i p}\right)$

Again a contradiction argument is enlightening. Suppose consumer type $i$ did not search for newly occupied housing in steady state. Remember now that a fraction of existing matched housing becomes vacant in every period, cost of searching and purchasing new housing for occupation is finite and marginal utility of occupied housing nears infinity as the occupied housing stock approaches 0. The supposition therefore implies that the consumer's marginal valuation of housing exceeds the cost of purchasing new housing for occupation in finite time. At that point, not searching for housing cannot be optimal for the consumer. Both consumer types searching must be part of any steady state solution.

Suppose now that both consumer types search for appropriate housing in steady state, but fundamental valuation of housing differs by type. Since both types must then (weakly) prefer searching to not searching, the type with higher fundamental valuation must strictly prefer searching. Optimally, the high fundamental valuation type should therefore raise search effort, increasing housing market tightness and search costs for both types until the lower valuation type is persuaded to quit searching. This contradicts a steady state in which both consumer types search actively for housing fit for occupation.

Implication 3.3. In any non-stochastic steady state:

- the patient consumer holds all equity and vacant housing

- the patient consumer (the marginal buyer), prices equity and after-search vacant housing

Intuitively, the patient consumer requires a lower rate of return to hold assets until the next period. The patient therefore price equity and vacant housing down to the level at which the impatient consumer leaves these markets. It follows that patient households hold all assets in steady state (as well as for small deviations around the steady state) ${ }^{38}$

\footnotetext{
${ }^{38}$ Appendix $\mathrm{D}$ besides formally verifying these statements, also proves existence of a unique welldefined steady state.
} 
Jointly, statements 3.2 and 3.3 lead to a key representational simplification of the model: in every period there exists a unique Nash bargained transaction price for housing. To understand why this is surprising, note that the Nash-bargained price depends on the payoffs and outside options of buyer and seller involved in a transaction. It follows that a model with two consumer types generally exhibits four different Nash bargained house prices (a price when the buyer is patient and the seller is patient, a price when the buyer is patient and the seller is impatient and so on).

In this specific modelling setup however, a unique Nash bargained transaction price emerges. Why? Notice implication 3.3 implies that the seller outside option does not depend on seller type. Because of the spot market in vacant housing, the outside option of both types equals the liquidation value of housing for a patient consumer. Because implication 3.2 shows that the buyer pay-off is independent of type, it therefore follows that, in this framework, the Nash-bargained price of all four buyer-seller type encounters is identical. While this setup is presumably not crucial (in a qualitative sense) for the main conclusions developed in this paper, it substantially increases transparency of model output (as well as the calibration procedure). Implication 3.4 summarizes this argument.

Implication 3.4. In any non-stochastic steady state:

- patient and impatient households face the same outside option during negotiations to sell a vacant house to a new occupant (the vacant house price)

- patient and impatient households face the same gain from successfully concluding negotiations to buy a vacant house for occupation (see fundamental value result for implication 3.2)

- by implication, all period $t$ matches lead to a transaction at the same price $q_{m, t}$ (irrespective of buyer and seller types involved)

\subsubsection{Why Does Expansionary Monetary Policy Raise The Housing Sales Rate?}

The interaction between housing market search frictions and house price Nash-bargaining offers a natural explanation for the section 1 finding that monetary policy stimulates housing liquidity. The argument relies on two steps. First, notice that the consumer optimality condition for buyer search effort $e_{t}$ implies free entry condition $3.20{ }^{39}$ In equilibrium, the net gain from purchasing a unit of housing equals expected search costs for buying that unit. Second, (and abstracting from house price rigidities) Nash bargaining in prices

\footnotetext{
${ }^{39}$ The free entry condition is already simplified taking into account local properties around the steady state summarized in implication 3.2
} 
implies that the buyer surplus from moving into a vacant house is proportional to the economic surplus accruing from the household-property match.

$$
\begin{aligned}
\underbrace{\frac{\kappa_{b}}{\theta_{t}^{1-\gamma}}}_{\text {Expected cost of buyer search }} & =\underbrace{V_{t}^{f}-q_{m, t}^{N}-F_{b}}_{\text {Buyer surplus }} \\
& =(1-\omega) \underbrace{\left(V_{t}^{f}-q_{v, t}-F_{s}-F_{b}\right)}_{\text {Total match surplus }}
\end{aligned}
$$

In combination, these two steps offer a story for the link between monetary policy and housing market liquidity. Temporary low interest rates raise the present value (in consumption terms) of the current and future flow of housing services to an occcupier household. This drives up the economic surplus from a match between household and property and, through Nash bargaining, the buyer payoff from purchasing a home. In equilibrium, more buyers enter the housing market, driving up search costs to the point that search costs equalize expected benefits from locating a house. From a seller perspective, in a market crowded with potential buyers, the rate at which vacant housing can be resold to new occupiers rises. 40

\subsubsection{Why Does A Higher Housing Sales Rate Raise Consumer Credit Ac- cess?}

In any period, a vacant house can be sold in two ways. First, a seller can offer the vacant property for sale on the search market for new occupants. If new occupants are found, then the vacant house can be sold at regular market price $q_{m, t}$. Second, if the search is unsuccessful, the seller can instantly sell the house on the period $t$ spot market to a speculator at price $q_{v, t}$. This speculator then effectively takes over the task of searching for a new occupier household in subsequent periods. The ratio between $q_{v, t}$ and $q_{m, t}$ therefore represents a fire sale discount reflecting costs for searching for a new end-user of the asset.

This fire sale discount plays a central role in the housing liquidity channel of monetary policy developed in this study. Notice first that a pricing equation for vacant property

\footnotetext{
${ }^{40}$ Two additional comments are useful at this point. First, key to this result is that buyers have bargaining power. This ensures that house prices rise by less than the change in fundamental housing value following a fall in interest rates. It follows that the sensitivity of housing liquidity to monetary policy rises in buyer bargaining power. Second, notice house price rigidities mean that house prices respond even more sluggishly to monetary policy than under Nash bargaining. Following the intuition in the main text, this makes buyer surplus and housing liquidity even more sensitive to changes in the policy rate.
} 
of the form studied in section 2 emerges naturally from the first order conditions of the patient consumer in this general equilibrium model. Rescaling equation 2.1 by current regular transaction price of housing yields an expression for the determinants of the fire sale discount (equation 3.21). Crucially, it depends on current and future measures of housing market tightness. When current and/or future housing sale rates are low, then searching for a new occupier of a vacant property is costly. It follows that speculators are only going to accept taking over the search process if the fire sale discount is large enough to compensate for high expected time-to-sale.

$$
\underbrace{\frac{q_{v, t}}{q_{m, t}}}_{\text {Sales rate }}=E_{t}\left(Q_{t+1}^{p} \frac{q_{m, t+1}}{q_{m, t}}(-\frac{m+\tau}{q_{m, t+1}}+\underbrace{P_{s, t}}_{\text {Satt }}\left(1+F_{s}-\frac{q_{v, t+1}}{q_{m, t+1}}\right)+\frac{q_{v, t+1}}{q_{m, t+1}})\right)
$$

Fire-sale discount

In turn, rewriting the impatient consumer credit constraint (that binds around steady state according to implication 3.1), the fire sale discount emerges as crucial determinant in household access to credit. The security offered to lenders by housing collateral depends inherently on the costs associated with liquidating that collateral in case of default 41 When liquidation costs are high because fire-sale discounts are large, then banks tighten credit access.

$$
\underbrace{b_{t}^{i p}}_{\text {Debt capacity }}=\underbrace{\frac{1}{E_{t}\left(Q_{t+1}^{p} \frac{R_{t}(1-z)}{\pi_{t+1}}\right)}}_{\text {Inverse bond return }} \underbrace{\frac{q_{v, t}}{q_{m, t}}}_{\text {Fire-sale discount }} \underbrace{q_{m, t} h_{t}^{i p}}_{\text {Value of housing }}
$$

Equations 3.21 and 3.22 therefore offer a natural argument suggesting that the housing sales rate response to monetary policy matters for the overall transmission process. By raising housing liquidity, monetary policy relaxes consumer credit constraints over and above the rise in regular book value of the housing stock.

\subsubsection{Why are backward-looking house prices needed to generate large hous- ing liquidity responses to monetary policy?}

Notice that the Nash bargaining price implies that buyer and seller suplus from matching a vacant house to a new household are positively related (see equation 3.23). Combined with

\footnotetext{
${ }^{41}$ Assuming that households can use equity and vacant housing to secure credit has no impact on the model solution. Around the steady state, borrowers will not choose to hold such asset types in equilibrium. Therefore, in either case occupied housing is the only collateral used by borrowers. Ruling these other asset classes out ex-ante has the advantage of reducing clutter in an already complex modelling setup.
} 
buyer free entry and a Cobb-Douglas matching technology, this generates a mechanism significantly dampening housing liquidity fluctuations.

Intuitively, buyers take advantage of low housing sale rates to drive down Nashbargained prices in negotiations (since the seller surplus from a transaction rises). In turn, this raises the ex-ante incentive to search for housing. The number of buyers in the housing market rises, housing liquidity rises and the original fall in house prices is dampened.

$$
\omega \underbrace{\left(V_{t}^{f}-\left(1+F_{b}\right) q_{m, t}^{N}\right)}_{\text {Buyer surplus from match }}=(1-\omega) \underbrace{\left(q_{m, t}^{N}\left(1-F_{s}\right)-q_{l, t}\right)}_{\text {Seller surplus from match }}
$$

As will be seen in the calibration of the subsequent section, the model therefore strongly suggests that house prices do not follow Nash-bargaining. Instead, house prices have a backward looking component. Buyers cannot instantly take advantage of the bad bargaining position of house sellers in illiquid property markets. In equilibrium, this amplifies the role of housing liquidity fluctuations.

\subsection{Calibration}

The quarterly calibration of the model follows a two-step procedure. Wherever possible, this study uses reference parameters from the literature. The housing search friction parameter $\gamma$, the house seller bargaining weight $\omega$, the size of the underlying monetary policy shock $\epsilon_{m, 1}$, the house price persistence parameter $s$ as well as the housing shock persistence parameter $\rho_{m}$ are set to match the empirical response of housing market and aggregate output to the Romer and Romer (2004) monetary policy shock.

As in Iacoviello (2005), set the yearly discount factors of patient and impatient households to 0.99 and 0.97 . This reflects estimates on the range of discount factors across the US population. ${ }^{42}$ Set labour market parameter $\chi_{l}=1$ and housing preference parameter $\chi_{h}=2.5$ (to ensure a steady state housing-gdp ratio of 6 ). Set a $75 \%$ Calvo price adjustment parameter $\vartheta$. Normalize productivity factor $A=1$ and the total housing supply $\bar{H}$ to 1 . Set the monetary policy response to output gap and inflation as in Iacoviello (2005) $\left(r_{y}=0.21\right.$ and $\left.r_{\pi}=0.16\right)$. Following convention, set labour wage elasticity to $\varphi=1$ and steady state mark-up $X^{*}=0.15$.

As in Ngai and Tenreyro (2009), set the rate at which housing is unmatched $z$ to $2.78 \%$ for consistency with an average stay in a house of 9 years ${ }^{43}$ Matching a steady

\footnotetext{
${ }_{42}^{4}$ Iacoviello (2005) cites the micro studies of Lawrance (1991), Carroll and Samwick (1997) and Samwick (1998) as sources of these ballpark estimates.

${ }^{43}$ N gai and Tenreyro (2009) in turn base their figures on median duration of stay in a house according to the American Housing Survey 1993-2005.
} 
state time-on-market for vacant housing of 5.7 months and a fire-sale discount of $15 \%$, set $m, \tau$ and $F_{s}$ following the calibration approach in section 2, Given lack of other information, assume buyer fixed costs are equal to the seller's $\left(F_{b}=F_{s}\right){ }^{44}$ Set $\kappa_{b}$ to ensure a steady state monthly sales rate of $20 \%$.

As in Monacelli (2009) and Sterk (2010), set the fraction of labour income going to patient households $\mu$ to 0.5 . This is close to the calibration used in Iacoviello (2005) and Iacoviello and Neri (2010). ${ }^{45}$ Considering the empirical literature, note that this number reflects Campbell and Mankiw (1989) who find that about 50\% of US households appear to behave as-if they were rule-of-thumb households (or credit-constrained) ${ }^{46}$ To ensure the assumption that the credit unconstrained own the wholesale firms does not affect relative economic weight of the two population groups, assume government lumpsum transfers $T_{t}^{i}$ to move $50 \%$ of wholesale firm revenues from the unconstrained to the constrained.

The housing search friction parameter $\gamma$, the house seller bargaining weight $\omega$, the size of the underlying monetary policy shock $\epsilon_{m, 1}$, the house price persistence parameters $s$ as well as the housing shock persistence parameter $\rho_{m}$ are set to minimize the squared distance between model and empirical impulse responses to monetary policy. Specifically, set target moments as first quarter and fourth quarter response of house price and housing sales rate. Additionally, set parameters to ensure that peak model and empirical response of output coincide 47 Formally, denoting by $u$ and $u^{e m p}$ respectively the model and empirical peak response of variable $x$ (in log-dev. from steady state), model parameters are chosen according to optimality criterion 3.25 .

\footnotetext{
${ }^{44}$ Some evidene in favour of such equal sharing of costs comes from Levitt and Syverson (2008). They report that real estate agents on buyer and seller side generally charge each about $3 \%$ of house price for their services.

${ }^{45}$ This number is slightly greater than the DSGE estimates in Iacoviello (2005) (64\%) and Iacoviello and Neri (2010) (using a Bayesian approach, they use a prior of $65 \%$ and find a mean posterior of $79 \%$ ). Attempting direct calibration of this parameter in this framework, results turned out to be very sensitive to other parameter choices. This study therefore chooses to postulate a reasonable value for this parameter exogenously.

${ }^{46}$ The Jappelli (1990) study might suggest that a baseline number $\mu=0.5$ is too low. He uses micro evidence from the 1983 Survey of Consumer Finances to identify that $20 \%$ of households either applied for a loan and were rejected or were deterred from applying because they expected rejection. However, this definition of the credit constrained may be more restrictive than that relevant for this study. For the purpose of this paper, the credit-constrained are those households whose terms of credit are sensitive to the debt capacity of their housing. This plausibly includes a much larger fraction of the population than those that are fully excluded from the credit market.

${ }^{47}$ Note that, in the model developed, output peaks on impact, while the Romer and Romer (2004) estimation results suggest a delayed output response. This weakness of the model is shared with many others. Christiano, Eichenbaum and Evans (2005) propose several bells and whistles to the baseline model that generate additional persistence in output and inflation impulse response functions. This paper refrains from introducing these additions in order to focus attention on the core features driving the housing liquidity channel of monetary policy.
} 


$$
\begin{gathered}
u=\left[\begin{array}{c}
\hat{P}_{s, 1} \\
\hat{P}_{s, 4} \\
\hat{q}_{m, 1} \\
\hat{q}_{m, 4} \\
\hat{y}_{1}
\end{array}\right] \\
\operatorname{Min}_{\omega, \gamma, s, \rho_{m}}\left(\frac{u-u^{e m p}}{u^{e m p}}\right)^{\prime}\left(\frac{u-u^{e m p}}{u^{e m p}}\right)
\end{gathered}
$$

The resulting calibration suggests setting $\gamma=0.1, \omega=0.19, \rho_{m}=0.8, s=0.33$ and $\epsilon_{m, 1}=0.007$. Intuitively, a low seller bargaining weight $\omega$ makes the buyer surplus especially sensitive to changes in the overall match surplus from occupying a house. A low $\gamma$ in turn ensures that changes in the buyer surplus lead to large equilibrium buyer entry into the housing market. These two parameter choices therefore contribute to making the housing sales rate sensitive to monetary policy. Equally, a low value for parameter $s$ ensures that house prices respond sluggishly to monetary policy, generating a humpshaped response in prices that further raises the responsiveness of housing liquidity to policy intervention. Table 1 summarizes the baseline calibration.

[Table 1 about here.]

\subsection{Counterfactual: Monetary Policy without Liquidity Effect}

To evaluate the contribution of the liquidity effect to macroeconomic transmission of monetary policy, consider a counterfactual scenario in which lenders are only allowed to raise loan amounts in line with house transaction price $q_{m}$ : modified borrowing constraint 3.26 holds. Effectively, this rule blends out the liquidity effect, since a direct link between transaction prices and borrowing limit is artificially imposed. Figures 8, 9, 10 and 11 consider the impact of a $1 \%$ monetary policy shock under the baseline model (solid line) and the counterfactual no-liquidity effect scenario (dashed line).

$$
E_{t}\left(Q_{t+1}^{i} \frac{R_{t}}{\pi_{t+1}}\right) b_{t}^{i} \leq \frac{q_{v}^{*}}{q_{m}^{*}} q_{m, t} h_{t}^{i}
$$

Consider first a monetary policy shock in the counterfactual no-liquidity effect model (dashed line). As in a standard New Keynesian model with perfect credit markets, the expansionary monetary policy shock lowers the returns on savings and encourages households to move consumption to the present. Because goods prices are sluggish, demand stimulates output, raises firm demand for labour inputs and starts a protracted period of inflation. Following the imposed Taylor rule, the nominal interest rate rises 
on impact to counteract the surge in output and inflation 48 Additionally, in this setup with credit-constrained households, lower interest rates raise the attractiveness of home ownership, driving up house prices. The borrowing-constrained can access more credit. They therefore buy more housing, they raise consumption disproportionally and they raise work effort by less than patient households (since current income is more valuable when credit constraints bind tightly) ${ }^{49}$

Consider now the response of the economy to monetary policy shocks in the full model (the solid line) that allows for interaction between housing search market and the credit market. Because the lower policy rate encourages buyers to enter the housing market, the housing sales rate rises. This boosts liquidation prices of housing by more than actual transaction prices 50 The fire-sale discount on property narrows and, following equation 3.22 , loan-to-value ratios offered by lenders rise. The housing liquidity effect roughly doubles the impact effect of monetary policy on debt expansion and output. Overall, these general equilibrium simulations suggest that the liquidity effect contributes substantially to the macroeconomic housing channel of monetary policy transmission.

[Figure 8 about here.]

[Figure 9 about here.]

[Figure 10 about here.]

[Figure 11 about here.]

\section{Liquidity Effect \& Home-Buyer Tax Credits}

If housing liquidity plays an important role in the housing channel of monetary policy transmission, then a natural question must be whether the liquidity effect also raises the macroeconomic impact of other policy levers that operate through the housing market. In other words, does ignoring the liquidity effect lead us to underestimate the impact of housing market interventions in general? The macroeconomic model developed in section

\footnotetext{
${ }^{48}$ Notice this positive interest rate response to the expansionary monetary policy shock is counterfactual (compared to the empirical results in section 1). However, it is shared with other papers in this modelling class (see for example Sterk (2010)). Furthermore, note that the real interest rate in fact does fall in response to the policy shock since the rise in inflation is large and protracted.

${ }^{49}$ In this setting, housing search frictions play a secondary role. Effectively, as more buyers enter the housing market after expansionary monetary policy, the search cost of looking for housing rises. However, search frictions only really start to matter for the rest of the economy once interaction between credit and search friction is introduced.

${ }^{50}$ Following the analysis in section 1 , liquidation values also rise because monetary expansion implies house price growth and liquidation values are forward-looking once an explicit time-to-sale assumption is introduced.
} 
3. calibrated using evidence on the housing and macroeconomic impact of monetary shocks, provides a natural environment in which to tackle this question.

A housing market intervention that received widespread coverage during the financial crisis of 2007-2009 will serve as inspiration for this exercise: the 8000 USD first time home-buyer tax credit towards purchase of new primary residences enacted by Congress on February 292009 as part of the American Recovery and Reinvestment Act (ARRA) (ultimately extended until summer 2010) 5152 Given an average transaction price of 292,600 USD for new homes sold in the United States in 2008 (according to Census Bureau statistics on new housing sales), this policy measure amounts to an effective subsidy of slightly less than $3 \%$ on average new US home purchases.

In the model of section 3 , such a temporary tax credit is proxied as a mean-reverting process that provides housing buyers with partial compensation for the fixed costs associated with housing purchase.

$$
s_{t}=\phi_{s} s_{t-1}+\epsilon_{s, t}
$$

The key equations of the baseline model affected by the subsidy are the Nash bargaining equation and the consumer budget constraint. The study assumes the subsidy is financed with equivalent lump-sum taxes for the two consumer types $T_{s, t}^{i}$.

$$
q_{m, t}\left(1-F_{s}\right)-q_{v, t}=\omega\left(V_{t}^{f}-q_{v, t}-\left(F_{s}+F_{b}-s_{t}\right) q_{m, t}\right)
$$

Figures 12, 13, 14 and 15 depict the response of the economy to a $3 \%$ shock to housing subsidy with persistence parameter $\phi_{s}=0.8$. Consider first the solid line impulse response functions of the full framework. In the first instance, the subsidy raises house prices, as sellers capture some of the greater value that buyers put on closing the property transaction. At the same time, lower ultimate transaction costs attract more buyers into the housing market, raising housing market liquidity. Both the fall in time-to-sale and higher transaction prices raise the liquidation value that lenders associate with property collateral. Credit-constrained households respond by increasing consumption and by purchasing more housing. This allows them to expand their entrepreneurial activity and to raise aggregate output.

Consider now again the artificial no-liquidity effect exercise from section 3 for the subsidy shock. The stimulus to aggregate consumption and output is substantially weakened. The peak output response to the tax credit is $1 / 3$ less. The housing liquidity effect introduced through housing search frictions plays a substantial role in the policy

\footnotetext{
${ }^{51}$ The act was preceded by another home buyer tax credit in 2008 in the form of an interest-free loan.

${ }^{52}$ The tax credit is limited to $10 \%$ of the house purchase price or 8000 USD. Recipients can add the tax credit to their tax refund (distinguishing the tax credit from a tax exemption).
} 
transmission process $5^{53}$

[Figure 12 about here.]

[Figure 13 about here.]

[Figure 14 about here.]

[Figure 15 about here.]

Overall, the simulations in this section suggest that the macroeconomic stimulus provided by the housing tax credit of 2009-2010 may be much larger than an evaluation according to price impact alone would imply. As the subsidy encourages home buyers to enter the housing market, it may have preserved housing collateral liquidity and stimulated a limited willingness of banks to provide households with mortgage finance in the crisis. The macroeconomic stimulus provided by housing market interventions should be judged based on their impact on both price and volume.

\section{Conclusions}

This paper shows that the impact of monetary policy on housing debt capacity is plausibly much greater than the response of property transaction prices alone suggests. When lenders evaluate the security provided by property collateral, they should not only take into account the eventual resale price of the house in case of default, but also the substantial carrying costs they face until an appropriate counterparty is found. Based on the empirical finding that a fall in interest rates substantially lowers the time-to-sale of housing, simulations show that this housing liquidity effect can play an important quantitative role (distinct from the standard house price effect) in the transmission of monetary policy to household credit access and the macroeconomy.

Calibrating the model to fit monetary policy impulse response functions, the simulated impact of a temporary home buyer tax credit on the macroeconomy also rises substantially once its combined impact on time-to-sale and housing transaction prices is taken into account. Direct intervention in the housing market may constitute a more powerful substitute for conventional monetary policy than standard analysis would suggest.

For policy makers, the crucial message of the paper is therefore that housing market policies need to be evaluated not only by their impact on prices, but also by their impact

\footnotetext{
${ }^{53}$ Overall, it should be noted that the impact of the housing subsidy on the macroeconomy appears generally very high in this calibrated DSGE model. Nonetheless, the simulations are instructive in illustrating that the housing liquidity channel of monetary policy plausibly plays an important role in determining the relative magnitude of credit frictions over the business cycle.
} 
on housing sales volume. Both price and volume plausibly matter for consumer access to mortgage credit. Having calibrated a macroeconomic model with borrowing-constrained households and housing market search frictions using empirical monetary policy impulse response functions, this study has developed a macroeconomic policy laboratory that takes into account both of these response dimensions.

This study naturally suggests several further avenues for research. First, to maintain links with the existing literature, this study has considered the impact of monetary policy in a macroeconomic model with one period risk-free mortgages. In light of the financial crisis of 2008-2009, introducing more realistic debt contracts constitutes an important step towards quantitatively meaningful macroeconomic models ${ }^{54}$ While the overall importance of the mechanism studied in this paper is conjectured to be robust to these extensions, exploring the exact quantitative implications of interaction between these refinements in the debt contracts and the liquidity effect is an important agenda item for further research.

Second, integrating housing market search frictions into a general equilibrium model of the US economy with credit-constrained households, this study proposes a theory for time-varying borrowing margins. In the face of a demand-slump, central banks face a trade-off between boosting demand through expansionary monetary policy and sowing the seeds of the next financial crisis by encouraging private sector leveraging. Analysing optimal monetary policy facing this trade-off requires at least a second-order approximation solution to the macroeconomic model developed and constitutes a potentially fruitful area for further research.

Third, the notion that asset debt capacity depends on the severity of resale market search frictions and fire-sale discounts offers a promising and tractable approach towards understanding fluctuations in credit access more generally. For example, the ability of the banking sector to sustain high leverage ratios may depend on the liquidity of the secondary market for the mortgage-backed securities (MBS) held by these institutions. Applying this search-theoretic approach to procyclical borrowing margins in over-thecounter financial asset markets is a fascinating topic for further research.

\footnotetext{
${ }^{54}$ Current research makes first steps in this direction. Forlati and Lambertini (2011) introduce risky mortgages in the DSGE framework. Calza, Monacelli and Stracca (2007) explore the impact of introducing long-term mortgages into macroeconomic general equilibrium setups.
} 


\section{References}

Adrian, Tobias, and Hyun Song Shin. 2010. "Liquidity and leverage." Journal of Financial Intermediation, 19(3): 418-437.

Albrecht, James, Axel Anderson, Eric Smith, and Susan Vroman. 2007. "Opportunistic Matching In The Housing Market." International Economic Review, 48(2): 641-664.

Andolfatto, David. 1996. "Business Cycles and Labor-Market Search." American Economic Review, 86(1): 112-32.

Andrew, Mark, and Geoffrey Meen. 2003. "House Price Appreciation, Transactions and Structural Change in the British Housing Market: A Macroeconomic Perspective." Real Estate Economics, 31(1): 99-116.

Bernanke, Ben, and Mark Gertler. 1989. "Agency Costs, Net Worth, and Business Fluctuations." American Economic Review, 79(1): 14-31.

Bernanke, Ben S., Mark Gertler, and Simon Gilchrist. 1999. "The financial accelerator in a quantitative business cycle framework." In Handbook of Macroeconomics. Vol. 1 of Handbook of Macroeconomics, , ed. J. B. Taylor and M. Woodford, Chapter 21, 1341-1393. Elsevier.

Brunnermeier, Markus K., and Lasse Heje Pedersen. 2009. "Market Liquidity and Funding Liquidity." Review of Financial Studies, 22(6): 2201-2238.

Calza, Alessandro, Tommaso Monacelli, and Livio Stracca. 2007. "Mortgage Markets, Collateral Constraints, and Monetary Policy: Do Institutional Factors Matter?" C.E.P.R. Discussion Papers CEPR Discussion Papers 6231.

Campbell, John Y., and N. Gregory Mankiw. 1989. "Consumption, Income and Interest Rates: Reinterpreting the Time Series Evidence." In NBER Macroeconomics Annual 1989, Volume 4. NBER Chapters, 185-246. National Bureau of Economic Research, Inc.

Campbell, John Y., Stefano Giglio, and Parag Pathak. 2009. "Forced Sales and House Prices." National Bureau of Economic Research, Inc NBER Working Papers 14866.

Carroll, Christopher D., and Andrew A. Samwick. 1997. "The nature of precautionary wealth." Journal of Monetary Economics, 40(1): 41-71. 
Christiano, Lawrence J., Martin Eichenbaum, and Charles L. Evans. 1999. "Monetary policy shocks: What have we learned and to what end?" In Handbook of Macroeconomics. Vol. 1 of Handbook of Macroeconomics, ed. J. B. Taylor and M. Woodford, Chapter 2, 65-148. Elsevier.

Christiano, Lawrence J., Martin Eichenbaum, and Charles L. Evans. 2005. "Nominal Rigidities and the Dynamic Effects of a Shock to Monetary Policy." Journal of Political Economy, 113(1): 1-45.

Davis, Morris A., and Jonathan Heathcote. 2005. "Housing And The Business Cycle." International Economic Review, 46(3): 751-784.

Eisfeldt, Andrea L. 2004. "Endogenous Liquidity in Asset Markets." Journal of Finance, 59(1): 1-30.

Fisher, Jonas D. M. 2007. "Why Does Household Investment Lead Business Investment over the Business Cycle?" Journal of Political Economy, 115: 141-168.

Forlati, Chiara, and Luisa Lambertini. 2011. "Risky Mortgages in a DSGE Model." International Journal of Central Banking, 7(1): 285-335.

Gali, Jordi. 2008. Monetary Policy, Inflation And The Business Cycle. Princeton University Press.

Geanakoplos, John. 2009. "The Leverage Cycle." Cowles Foundation for Research in Economics, Yale University Cowles Foundation Discussion Papers 1715.

Genesove, David, and Christopher Mayer. 2001. "Loss Aversion And Seller Behavior: Evidence From The Housing Market." The Quarterly Journal of Economics, 116(4): 1233-1260.

Hart, Oliver, and John Moore. 1994. "A Theory of Debt Based on the Inalienability of Human Capital." The Quarterly Journal of Economics, 109(4): 841-79.

Hedlund, Aaron. 2011. "The Cyclical Behavior of Housing, Illiquidity and Foreclosures." University of Pennsylvania Working paper.

Hort, Katinka. 2000. "Prices and turnover in the market for owner-occupied homes." Regional Science and Urban Economics, 30(1): 99-119.

Hsieh, Chang-Tai, and Enrico Moretti. 2003. "Can Free Entry Be Inefficient? Fixed Commissions and Social Waste in the Real Estate Industry." Journal of Political Economy, 111(5): 1076-1122. 
Iacoviello, Matteo. 2005. "House Prices, Borrowing Constraints, and Monetary Policy in the Business Cycle." American Economic Review, 95(3): 739-764.

Iacoviello, Matteo, and Stefano Neri. 2010. "Housing Market Spillovers: Evidence from an Estimated DSGE Model." American Economic Journal: Macroeconomics, $2(2): 125-64$.

Jappelli, Tullio. 1990. "Who Is Credit Constrained in the U.S. Economy?" The Quarterly Journal of Economics, 105(1): 219-34.

Kiyotaki, Nobuhiro, and John Moore. 1997. "Credit Cycles." Journal of Political Economy, 105(2): 211-48.

Krainer, John. 2001. "A Theory of Liquidity in Residential Real Estate Markets." Journal of Urban Economics, 49(1): 32-53.

Kurlat, Pablo. 2009. "Lemons, Market Shutdowns And Learning." Working Paper.

Lawrance, Emily C. 1991. "Poverty and the Rate of Time Preference: Evidence from Panel Data." Journal of Political Economy, 99(1): 54-77.

Levitt, Steven D., and Chad Syverson. 2008. "Market Distortions When Agents Are Better Informed: The Value of Information in Real Estate Transactions." The Review of Economics and Statistics, 90(4): 599-611.

Mayer, Christopher J. 1998. "Assessing the Performance of Real Estate Auctions." Real Estate Economics, 26(1): 41-66.

Merz, Monika. 1995. "Search in the labor market and the real business cycle." Journal of Monetary Economics, 36(2): 269-300.

Milbradt, Konstantin, and Zhiguo He. 2012. "Endogenous Liquidity and Defaultable Bonds." MIT Working paper.

Monacelli, Tommaso. 2009. "New Keynesian models, durable goods, and collateral constraints." Journal of Monetary Economics, 56(2): 242-254.

Ngai, L. Rachel, and Silvana Tenreyro. 2009. "Hot and Cold Seasons in the Housing Market." Centre for Economic Performance, LSE CEP Discussion Papers dp0922.

Novy-Marx, Robert. 2009. "Hot and Cold Markets." Real Estate Economics, 37(1): 122 . 
Piazzesi, Monika, and Martin Schneider. 2009. "Momentum Traders in the Housing Market: Survey Evidence and a Search Model." American Economic Review, 99(2): 406-11.

Pissarides, Christopher. 2000. Equilibrium Unemployment Theory. MIT Press.

Poterba, James M. 1991. "House Price Dynamics: The Role of Tax Policy." Brookings Papers on Economic Activity, 22(2): 143-204.

Romer, Christina D., and David H. Romer. 2004. "A New Measure of Monetary Shocks: Derivation and Implications." American Economic Review, 94(4): 1055-1084.

Samwick, Andrew A. 1998. "Discount rate heterogeneity and social security reform." Journal of Development Economics, 57(1): 117-146.

Shleifer, Andrei, and Robert W Vishny. 1992. "Liquidation Values and Debt Capacity: A Market Equilibrium Approach." Journal of Finance, 47(4): 1343-66.

Simsek, Alp. 2012. "Belief Disagreements and Collateral Constraints." Harvard University Working paper.

Stein, Jeremy C. 1995. "Prices and Trading Volume in the Housing Market: A Model with Down-Payment Effects." The Quarterly Journal of Economics, 110(2): 379-406.

Sterk, Vincent. 2010. "Credit frictions and the comovement between durable and nondurable consumption." Journal of Monetary Economics, 57(2): 217-225.

Wheaton, William C. 1990. "Vacancy, Search, and Prices in a Housing Market Matching Model." Journal of Political Economy, 98(6): 1270-92.

Williams, Joseph T. 1995. "Pricing Real Assets with Costly Search." Review of Financial Studies, 8(1): 55-90. 


\section{A Robustness Checks for Section 1}

This section considers two robustness checks for the results in section 1. It confirms that the strong response of housing sales rate to monetary policy is not purely an artefact of the Romer and Romer (2004) monetary policy shock identification scheme. It also confirms that the new housing sales rate is not the only measure of housing liquidity that rises substantially given expansionary monetary policy.

To tackle the first point, figure 16 replicates the results in section 1 using a quarterly recursive Vector-Autoregressions identification scheme (this method is reviewed for example in Christiano, Eichenbaum and Evans (1999)). The identification ordering assumes that output and price level do not respond contemporaneously to monetary policy. The housing variables can respond contemporaneously. The VAR includes a constant, a linear trend and seasonal dummies.

Romer and Romer (2004) find that their identification scheme leads to large estimates for the macroeconomic response to monetary policy (relative to the recursive identification scheme). Figures 3 and 16 reveal that this finding carries over to the housing market response. Key however is that the sales rate response remains significantly more pronounced than the response of transaction prices under the recursive identification scheme.

To tackle the second point, figure 17 shows the response of other proxies for housing liquidity to Romer and Romer (2004) monetary policy shocks. The data sources are summarized in section B. Notice first that the strong response of new housing sale rates is reflected in an actual increase in transaction volumes both for new and existing properties. 55

Equally, figure 17 shows that the dampening of the new housing sales rate response after two years roughly coincides with a substantial rise of for-sale new housing on the market. The construction sector responds to a hot housing market by raising supply. This response is not captured in the DSGE model of section 3 where a constant total housing supply is assumed. Note however that, from the standpoint of the lender decision in the model, the ratio of sales to for-sale housing is key to evaluate the security provided by housing collateral.

Finally, figure 17 also reports the response of the median months new houses are reported for sale. This measure behaves very similarly to the housing sales rate considered in the main text.

\footnotetext{
${ }^{55}$ The fact that existing housing responds with a lag, while new housing sale numbers jump on impact of the monetary policy shock, reflects differences in the way these two statistics are collected. The new housing sales measure captures when the sales contract is signed, while an existing housing sale is recorded at the close of the sale (when the mortgage has been approved and the transfer of funds has taken place). This can explain a response lag of a month or two.
} 
[Figure 16 about here.]

[Figure 17 about here.]

\section{B Data Sources}

Table 2 summarizes the data sources used in this study $\sqrt[56]{57}$

[Table 2 about here.]

\section{Characterizing Optimality Conditions for the Con- sumer in Section 3}

Consider the consumer problem described in section 3. The associated first order conditions are key drivers of the macroeconomic mechanism behind this paper. First, for notation, it is useful to introduce the shadow price of vacant housing before search in period $t\left(q_{v b, t}\right)$. Irrespective of consumer type, this is given by:

$$
q_{v b, t}=-m-\tau+P_{s}\left(\theta_{t}\right) q_{m, t}+\left(1-P_{s}\left(\theta_{t}\right)\right) q_{v, t}
$$

Second, for any type $i$, either the price of a vacancy at the end of period $t$ equals the present discounted value of a vacancy at the start of period $t+1$, or no vacant property is held by that type at the end of period $t$.

$$
q_{v, t} \geq E_{t}\left(Q_{t+1}^{i} q_{v b, t+1}\right) ; v_{t}^{i} \geq 0 ;\left(q_{v, t}-E_{t}\left(Q_{t+1}^{i} q_{v b, t+1}\right)\right) v_{t}^{i}=0
$$

Third, the fundamental (shadow) value of occupied housing $V_{t}^{f}$ equals its current consumption-equivalent service value, its present discounted future value (either as matched house or as newly unmatched house) as well as its value as collateral asset to access debt finance (where the Lagrangian $\lambda_{t}$ denotes the consumption-equivalent value of collateral).

$$
V_{t}^{f, i}=j \frac{c_{t}^{i}}{h_{t}^{i}}+E_{t}\left(Q_{t+1}^{i}\left(-m-\tau+z q_{v b, t+1}+(1-z) V_{t+1}^{f, i}\right)\right)+\lambda_{t}^{i} \frac{1}{E_{t}\left(Q_{t+1}^{i} \frac{R_{t}(1-z)}{\pi_{t+1}}\right)} q_{v, t}
$$

\footnotetext{
${ }^{56}$ Alternative popular house price indexes such as the FHFA index and the S\&P/Case-Shiller index are available only starting in the early 1990s, precluding their use in conjunction with the Romer and Romer (2004) policy shocks. Using the U.S. Census Bureau index of purchase prices on new single-family homes (available since 1963) leads to a larger peak response of house prices at $4 \%$. The FMHPI index is used in the main text, since (i) its repeat-sales methodology controls for variation in the quality of housing sold and (ii) it considers the value of both new and existing housing.

${ }^{57}$ House prices are reported in real terms by deflating with the CPI price index measure
} 
Fourth, consumers undertake search effort for housing up to the point where marginal benefit equals marginal cost. In effect, this links equilibrium sales probability to the difference between fundamental housing value and the current bargained transaction price when housing fit for occupation is found 58 Note that, if both patient and impatient consumers have put effort into search, then in equilibrium the free entry condition must equalize perceived fundamental value across types. As will be shown, this condition will hold in the neighbourhood of the deterministic steady state.

$$
V_{t}^{f, i} \leq \frac{\kappa_{b}}{\operatorname{Pr}_{b}\left(\theta_{t}\right)}+q_{m, t} ; e_{t}^{i} \geq 0 ;\left(V_{t}^{f, i}-\left(\frac{\kappa_{b}}{P r_{b}\left(\theta_{t}\right)}+q_{m, t}\right)\right) e_{t}^{i}=0
$$

Fifth, the Euler equation ensures consumption is optimally allocated across time, given rates of return available and the borrowing constraint.

$$
1=E_{t}\left(Q_{t+1}^{i} \frac{R_{t}}{\pi_{t+1}}\right)+\lambda_{t}^{i}
$$

Sixth, in equilibrium, either the stock price equals the present discounted value of future dividend and capital gain for consumer type $i$, or no equity is held by that subgroup of the population.

$$
q_{o, t} \geq E_{t}\left(Q_{t+1}^{i}\left(q_{o, t+1}+\Pi_{t+1}\right)\right) ; o_{t} \geq 0 ;\left(q_{o, t}-\left(E_{t}\left(Q_{t+1}^{i}\left(q_{o, t+1}+\Pi_{t+1}\right)\right)\right)\right) o_{t}=0
$$

Seventh, the intratemporal labour-consumption first order condition ensures workers optimally trade-off the utility cost of providing additional labour against the consumption gains from greater labour income.

$$
\frac{w_{t}}{c_{t}^{i}}=\chi\left(l_{t}^{i}\right)^{\eta}
$$

Eighth, the Lagrangian for the borrowing constraint is zero if the borrowing constraint does not bind:

$$
E_{t}\left(Q_{t+1}^{i} \frac{R_{t}}{\pi_{t+1}}\right) b_{t}^{i} \leq q_{v, t} h_{t}^{i} ; \lambda_{t} \geq 0 ;\left(E_{t}\left(Q_{t+1}^{i} \frac{R_{t}}{\pi_{t+1}}\right) b_{t}^{i}-q_{v, t} h_{t}^{i}\right) \lambda_{t}=0
$$

The first order conditions of the wholesale producer and retailer follow the standard textbook.

\footnotetext{
${ }^{58}$ Note this condition offers an analogue to the free entry condition for vacancy posting in the labour market search literature (see Pissarides (2000)).
} 


\section{Characterizing the Steady State in Section 3}

This section describes the steady state (the deterministic solution of the model in a setting without stochastic shocks) of section 3 in a series of propositions. Denote steady state variables by a star subscript.

Proposition 1. In any steady state of the model, the patient consumer is not credit constrained.

Proof of proposition 1: Assume the patient consumer credit constrained. Then we have $\left(b^{p}\right)^{*}>0$ and, using C.8, the shadow value of funds is strictly positive for patient consumers $\left(\left(\lambda^{p}\right)^{*}>0\right)$. Note now by the bond market clearing this implies $\left(b^{i p}\right)^{*}=$ $-\left(b^{p}\right)^{*}<0$ and, using C.8, the shadow value of funds for the impatient must be zero $\left(\left(\lambda^{i p}\right)^{*}=0\right)$. Subtract now the Euler equations C.5 of the two types to get:

$$
0=\left(\beta^{p}-\beta^{i p}\right) R^{*}+\left(\lambda^{p}\right)^{*}
$$

Since $R^{*}>0$ in a well-defined steady state, this implies $\beta^{i p}>\beta^{p}$. This contradicts the definition of patient and impatient consumers $\left(\beta^{i p}<\beta^{p}\right)$.

Proposition 2. In any steady state of the model, the impatient consumer is credit constrained.

Proof of proposition 2: Assume the impatient consumer is not credit constrained in steady state. Since we have established that the patient consumer must not be credit constrained in steady state, by equation C.8, the shadow value of funds is zero for both types: $\lambda^{i p}=\lambda^{p}=0$. Using equation C.5 this implies $1=\beta^{p} R^{*}$ and $1=\beta^{i p} R^{*}$. Subtracting these two statements yields $0=\left(\beta^{p}-\beta^{i p}\right) R^{*}$. Since $R^{*}>0$ in a well-defined steady state, this implies $\beta^{p}=\beta^{i p}$. But this contradicts the assumption that there is a patient and impatient consumer type $\left(\beta^{p}>\beta^{i p}\right)$.

Proposition 3. In any steady state of the model, both consumer types search for new housing for occupation.

Proof of proposition 3. Assume consumer of type $i$ did not search in steady state $\left(e^{i}\right)^{*}=0$. By the dynamic equation for occupied housing held by type $i$ consumers 3.3 , this implies that the consumer does not occupy any housing in steady state $\left(\left(h^{i}\right)^{*}=\right.$ $0)$. But then the fundamental value of housing is undefined, since the fundamental housing value equation C.3 implies $\lim _{\left(h^{i}\right)^{*} \downarrow 0}\left(V^{i, f}\right)^{*}=+\infty$. The first order condition C.4 $\left(\left(V^{i, f}\right)^{*} \leq \frac{\kappa_{b}}{\operatorname{Pr}_{b}\left(\theta_{t}\right)}+q_{m, t}\right)$ cannot hold.

Proposition 4. In any steady state of the model, both consumer types occupy housing. 
Proof of proposition 4: The proof for this statement follows straightforwardly combining proposition 3 and the equation for housing dynamics 3.3 .

Proposition 5. In any steady state of the model, both consumer types have the same fundamental valuation of housing.

Proof of proposition 5. Since $\left(e^{i}\right)^{*}>0$ for both types, free entry condition C.4 implies that $\left(V^{i, f}\right)^{*}=\frac{\kappa_{b}}{P r_{b}\left(\theta_{t}\right)}+q_{m, t}$. Subtracting the statement across types yields: $\left(V^{p, f}\right)^{*}=\left(V^{i p, f}\right)^{*}$.

Proposition 6. In any steady state of the model, the patient agent holds all firm equity.

Proof of proposition 6: At least one consumer type must hold all equity, since the equity market clears in equilibrium and equity is in positive supply. Assume now that both types hold equity in steady state. Then first order condition C.6 implies: $\left(q_{o}\right)^{*}=\beta_{i}\left(\left(q_{o}\right)^{*}+\right.$ $\left.\Pi^{*}\right)$. Subtracting this equation by consumer type yields: $0=\left(\beta_{p}-\beta_{i p}\right)\left(\left(q_{o}\right)^{*}+\Pi^{*}\right)$. Since $\left(\left(q_{o}\right)^{*}+\Pi^{*}\right)>0$ in a well-defined steady state, this implies $\beta_{p}=\beta_{i p}$. But this contradicts the assumption that there is a patient and impatient consumer type $\left(\beta_{p}>\beta_{i p}\right)$.

Proposition 7. In any steady state of the model, the patient agent holds all end-of-period vacant property and physical capital.

Proof of proposition 7) The proof of this proposition follows directly the pattern of the argument for proposition 6 .

\section{E Derivation of Section 2.1 Log-Linearization Result}

Taking a first order $(\log )$ Taylor approximation of equation 2.1 yields equation E.1.

$$
q_{v}^{*} \hat{q}_{v, t}=q_{v}^{*} \hat{Q}_{t+1}+\left[Q^{*}\left(q_{m}^{*}\left(1-F_{s}\right)-q_{v}^{*}\right)\right] \hat{P}^{s, t+1+\left[Q^{*} P_{s}^{*}\left(1-F_{s}\right)\right] \hat{q}_{m, t+1}}+Q^{*} q_{v}^{*}\left(1-P_{s}^{*}\right) \hat{q}_{v, t+1}
$$

Defining $\rho_{1}=\frac{Q^{*}\left(q_{m}^{*}\left(1-F_{s}\right)-q_{v}^{*}\right) P_{s}^{*}}{q_{v}^{*}}, \rho_{2}=\frac{Q^{*} P_{s}^{*} q_{m}^{*}\left(1-F_{s}\right)}{q_{v}^{*}}$ and $\rho_{3}=Q^{*}\left(1-P_{s}^{*}\right)$ we can rewrite this as equation E.2.

$$
\hat{q}_{v, t}=E_{t}\left(\hat{Q}_{t+1}+\rho_{1} \hat{P}_{s, t+1}+\rho_{2} \hat{q}_{m, t+1}+\rho_{3} \hat{q}_{v, t+1}\right)
$$

Log-linearization of expression 2.2 yields expression E.3. Inserting E.3 in E.2 an iterating forward yields expression 2.3 in the main text.

$$
E_{t}\left(\hat{Q}_{t+1}\right)=-\hat{r}_{f, t+1}
$$




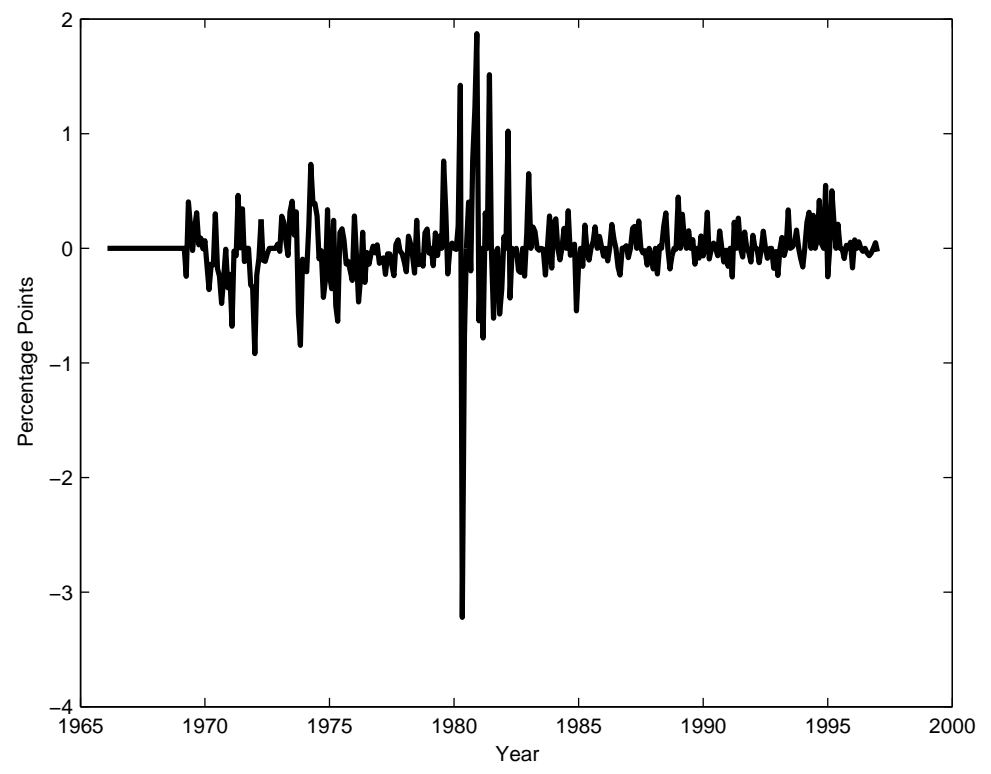

Figure 1: The Romer and Romer (2004) monetary policy shock series 

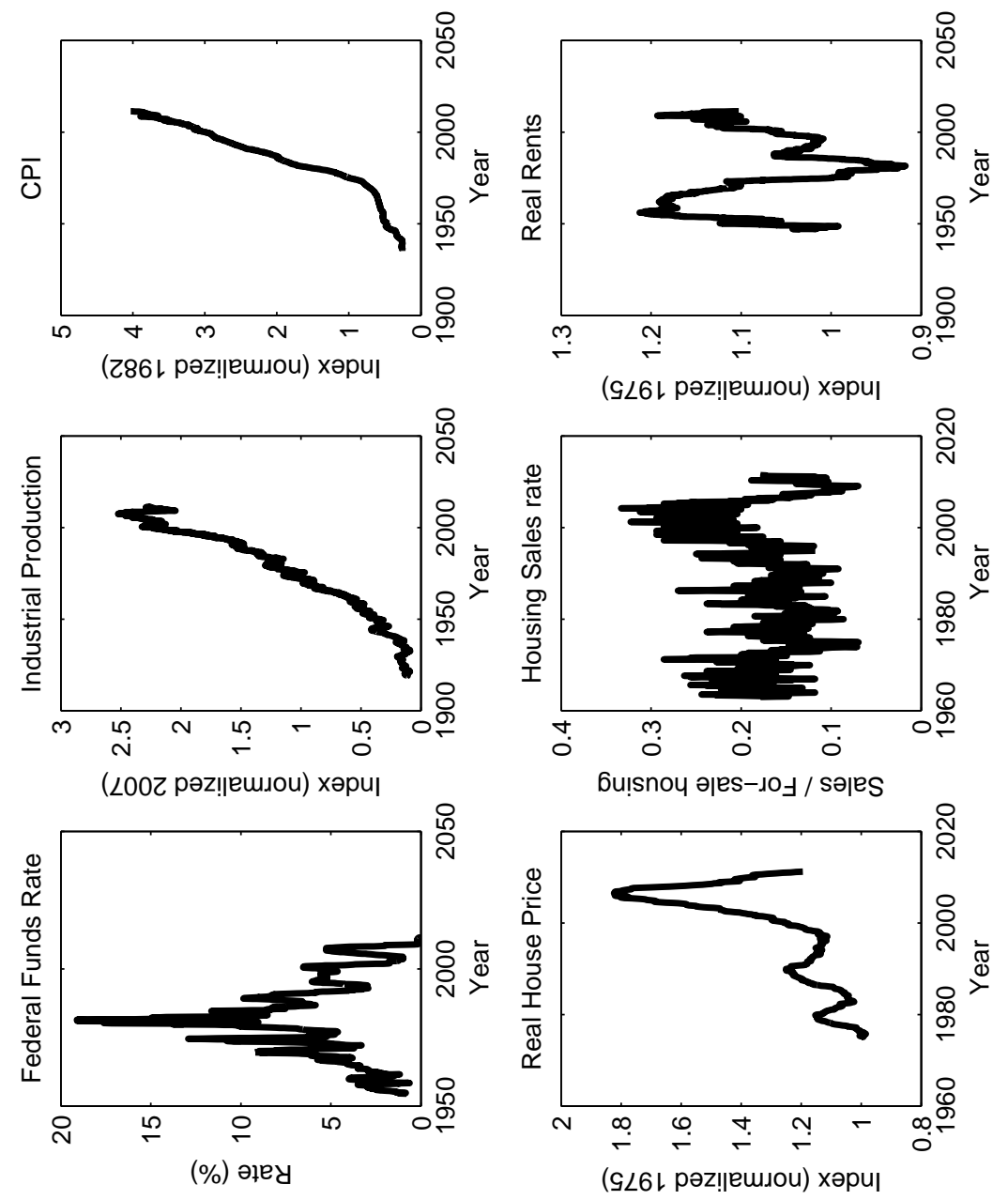

Figure 2: Raw time series 

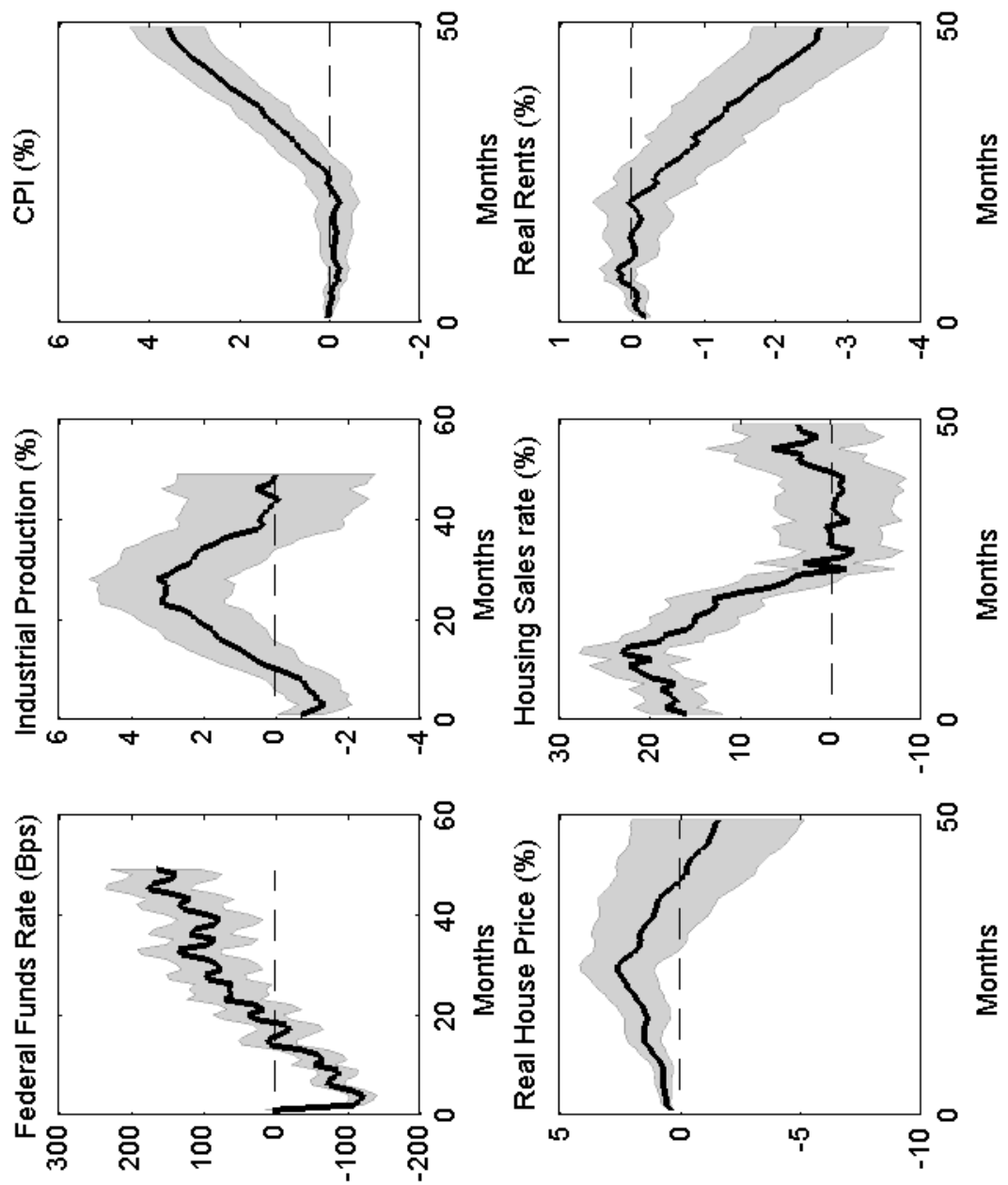

Figure 3: Response of the housing market (Romer and Romer (2004) shocks; in log dev. from trend; $95 \%$ confidence intervals) 


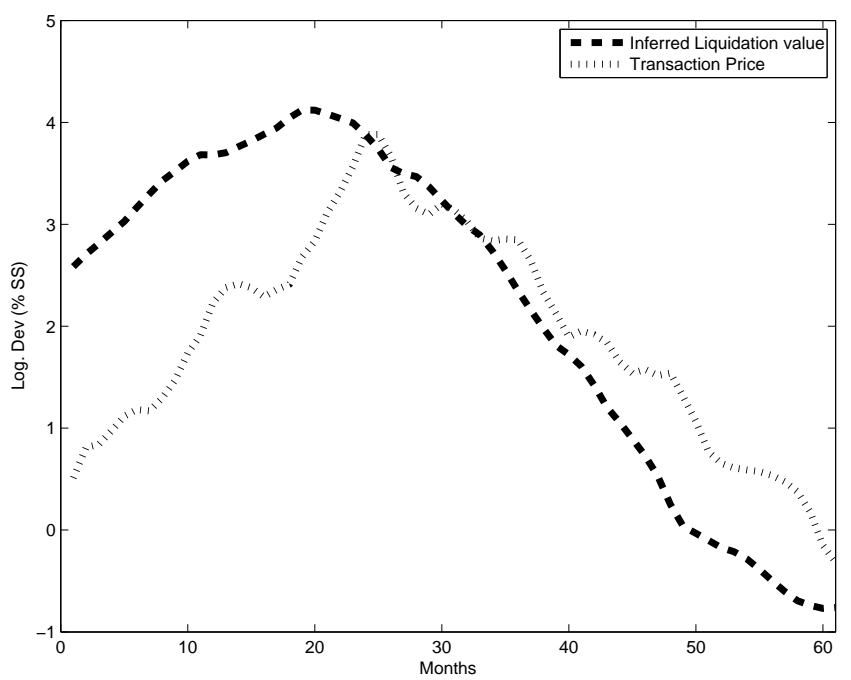

Figure 4: Response of liquidation value to temporary $1 \%$ exogenous fall in federal funds rate 


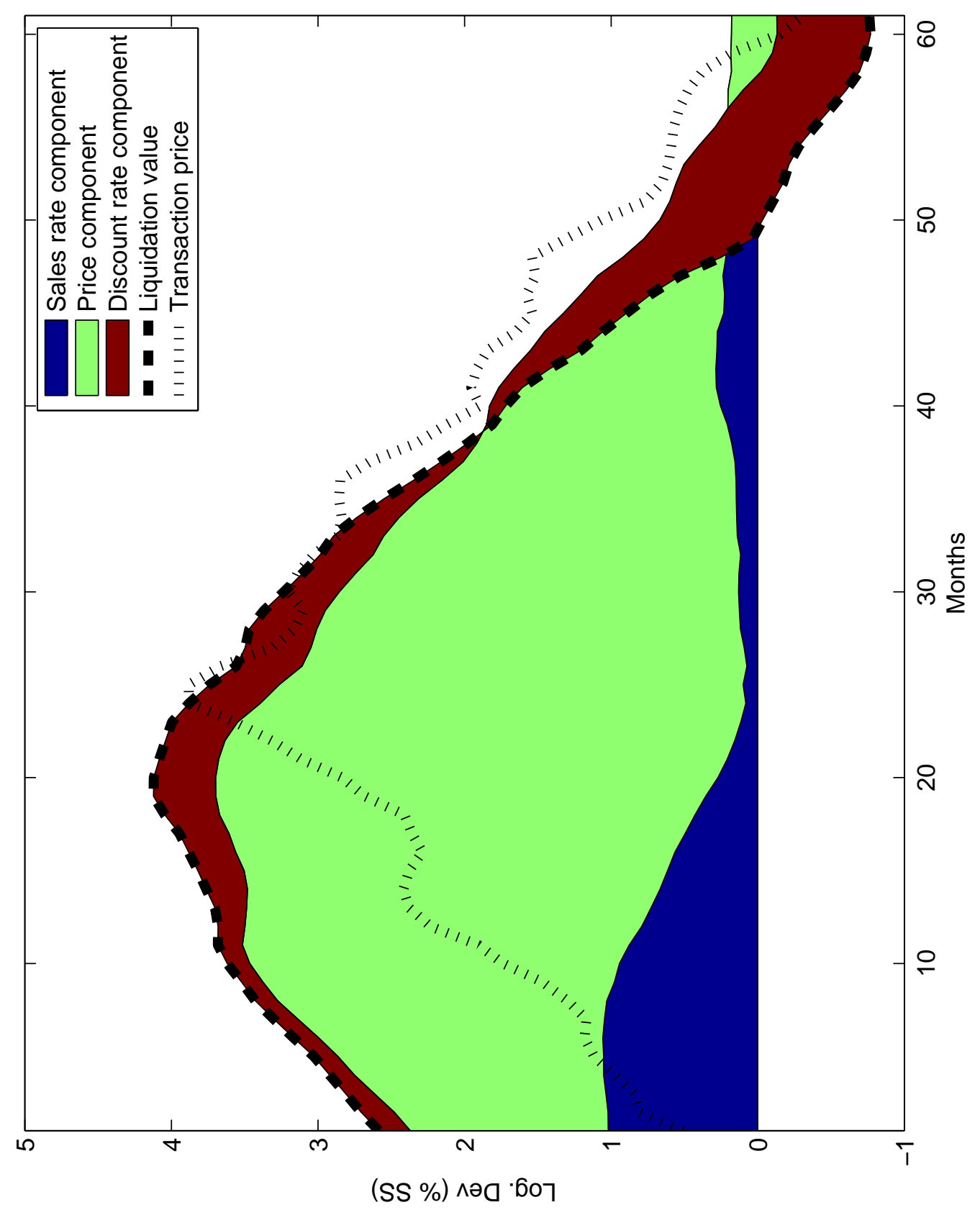

Figure 5: Response of liquidation value to temporary $1 \%$ exogenous fall in federal funds rate 


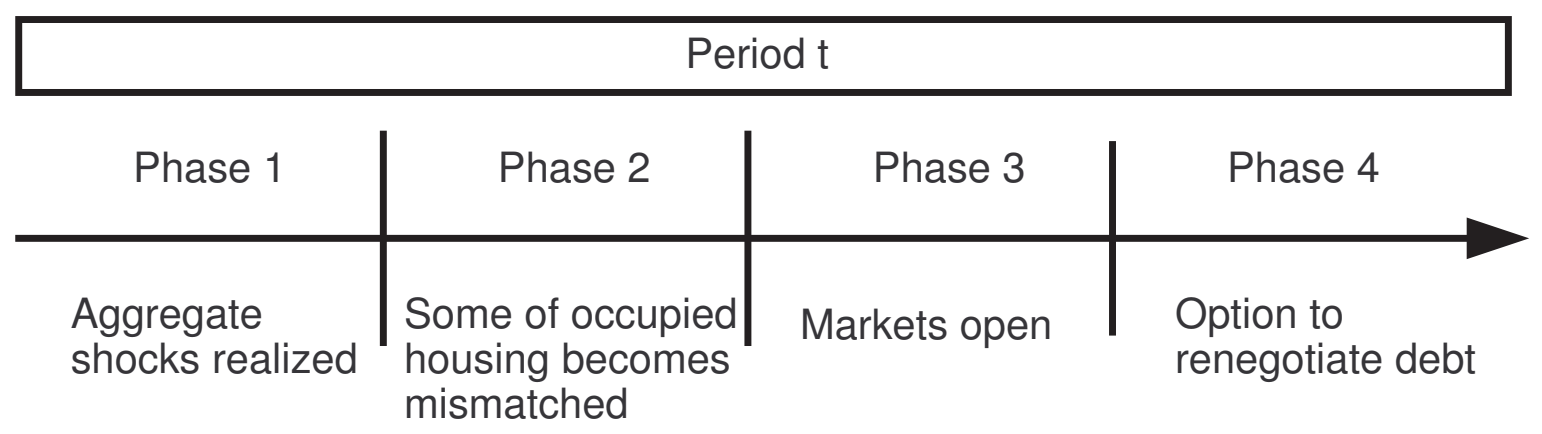

Figure 6: Period t consists of four distinct phases 
Labor market (w_t)

\begin{tabular}{|l|l|}
\hline $\begin{array}{l}\text { Search market for } \\
\text { housing fit for } \\
\text { occupation (q_mt) }\end{array}$ & $\begin{array}{l}\text { Spot market for } \\
\text { foreclosures after } \\
\text { matches with new } \\
\text { occupants (q_vt) }\end{array}$ \\
\hline
\end{tabular}

Firm equity (o_t)

Goods market (1)

Bond market (r_t)

Figure 7: Schematic for markets in the model economy 

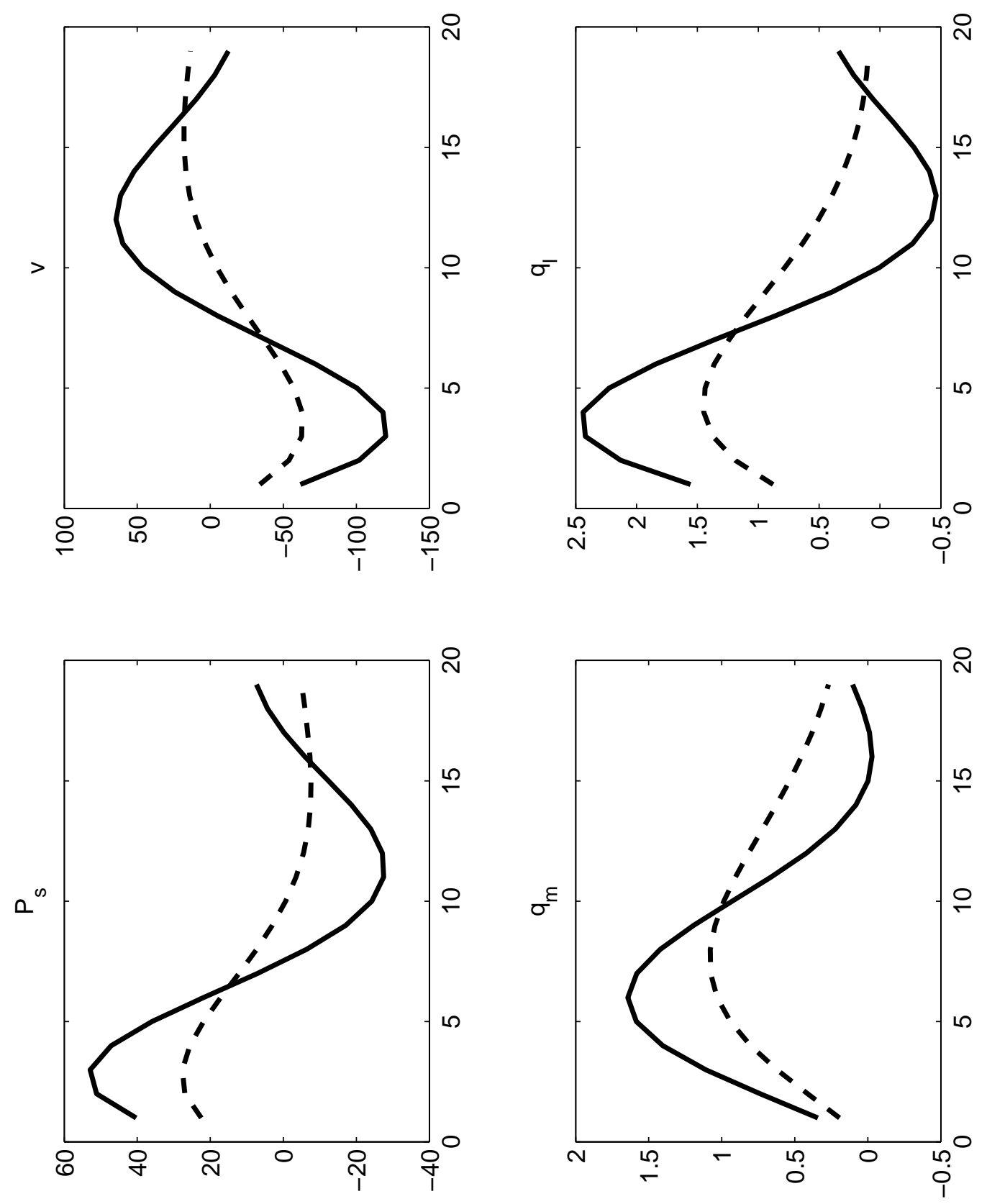

Figure 8: Simulated monetary policy IRF (\% dev SS) baseline model (solid line) and the counterfactual no-liquidity effect scenario (dashed line) 

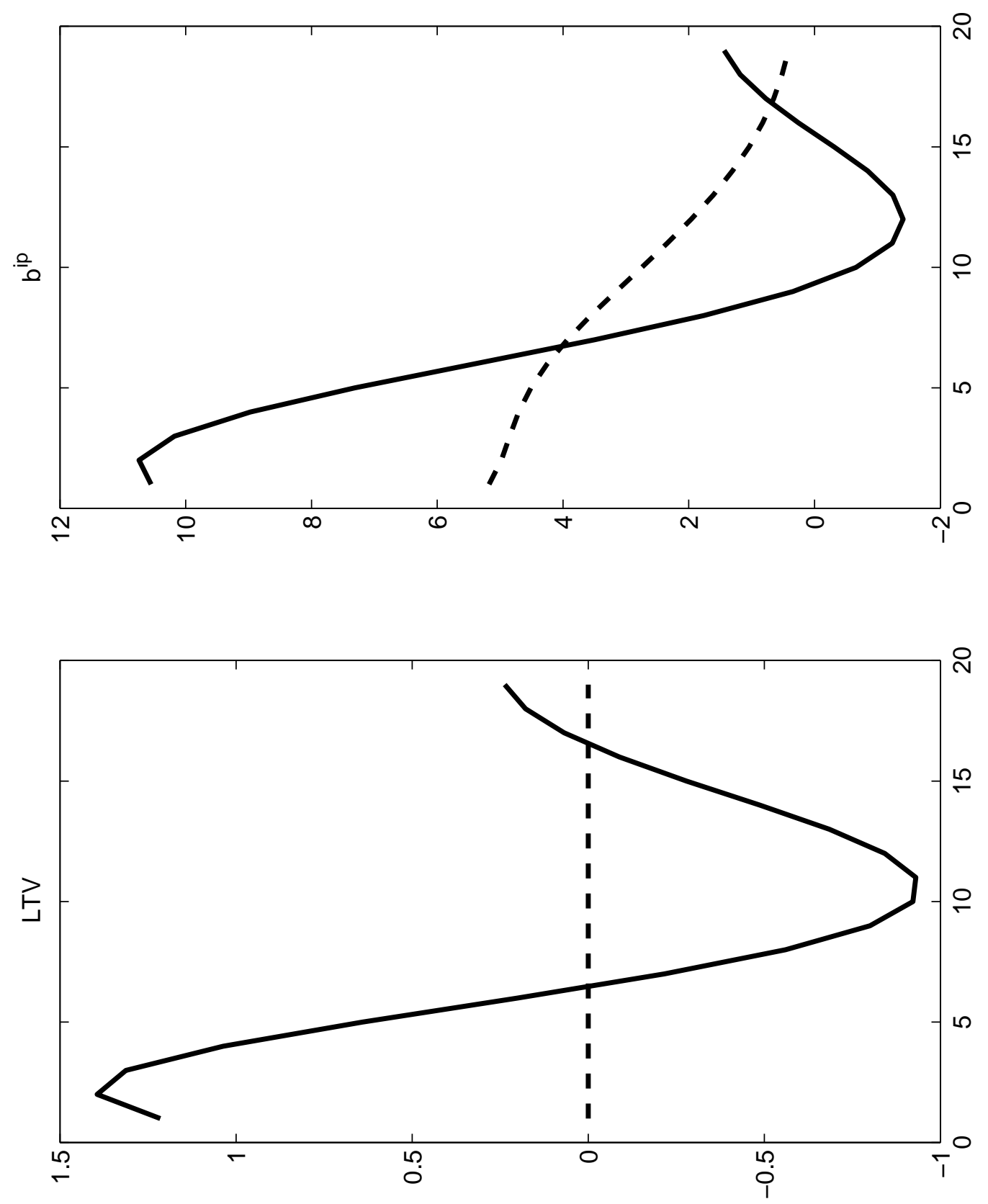

Figure 9: Simulated monetary policy IRF (\% dev SS) baseline model (solid line) and the counterfactual no-liquidity effect scenario (dashed line) 

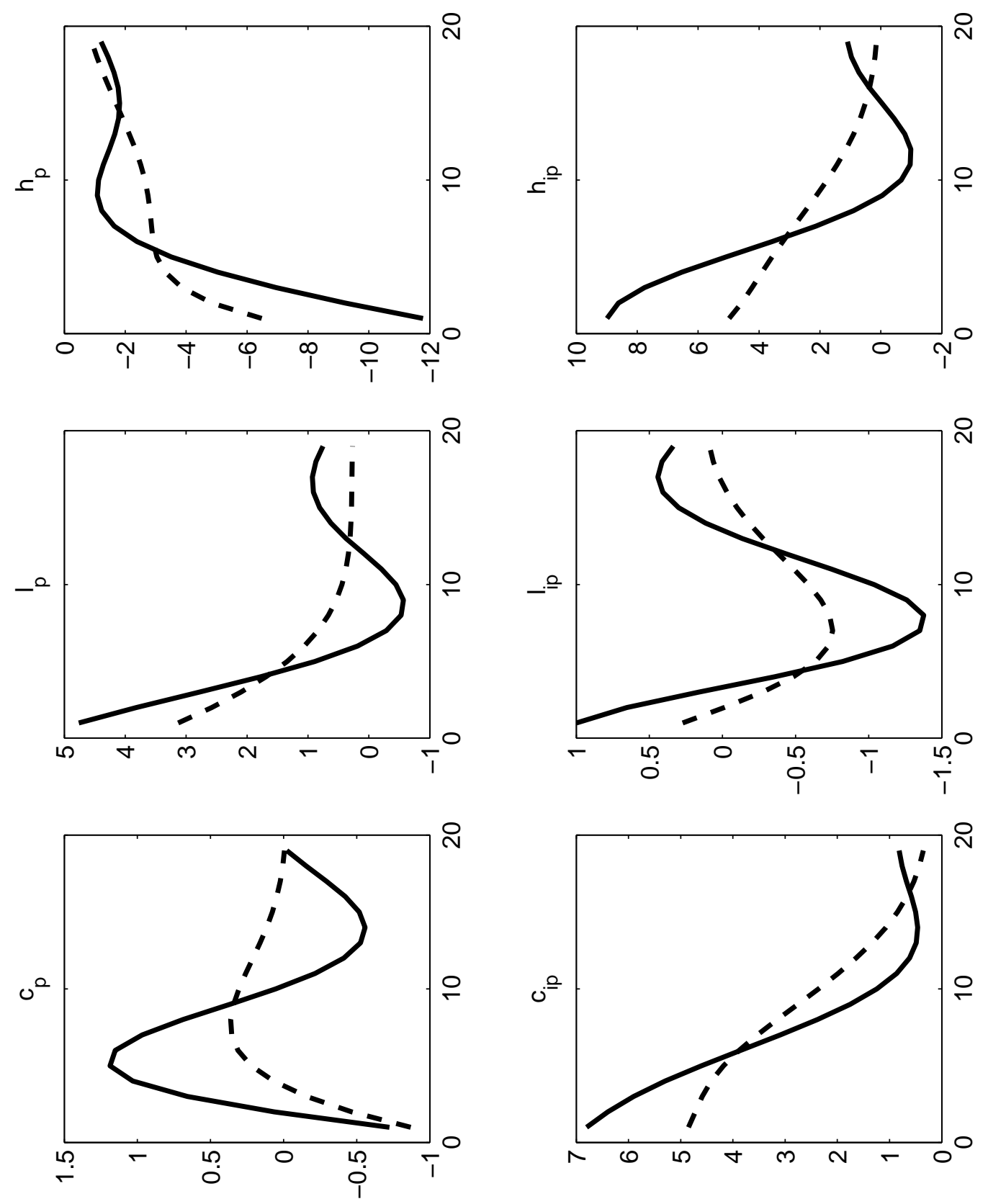

Figure 10: Simulated monetary policy IRF (\% dev SS) baseline model (solid line) and the counterfactual no-liquidity effect scenario (dashed line) 

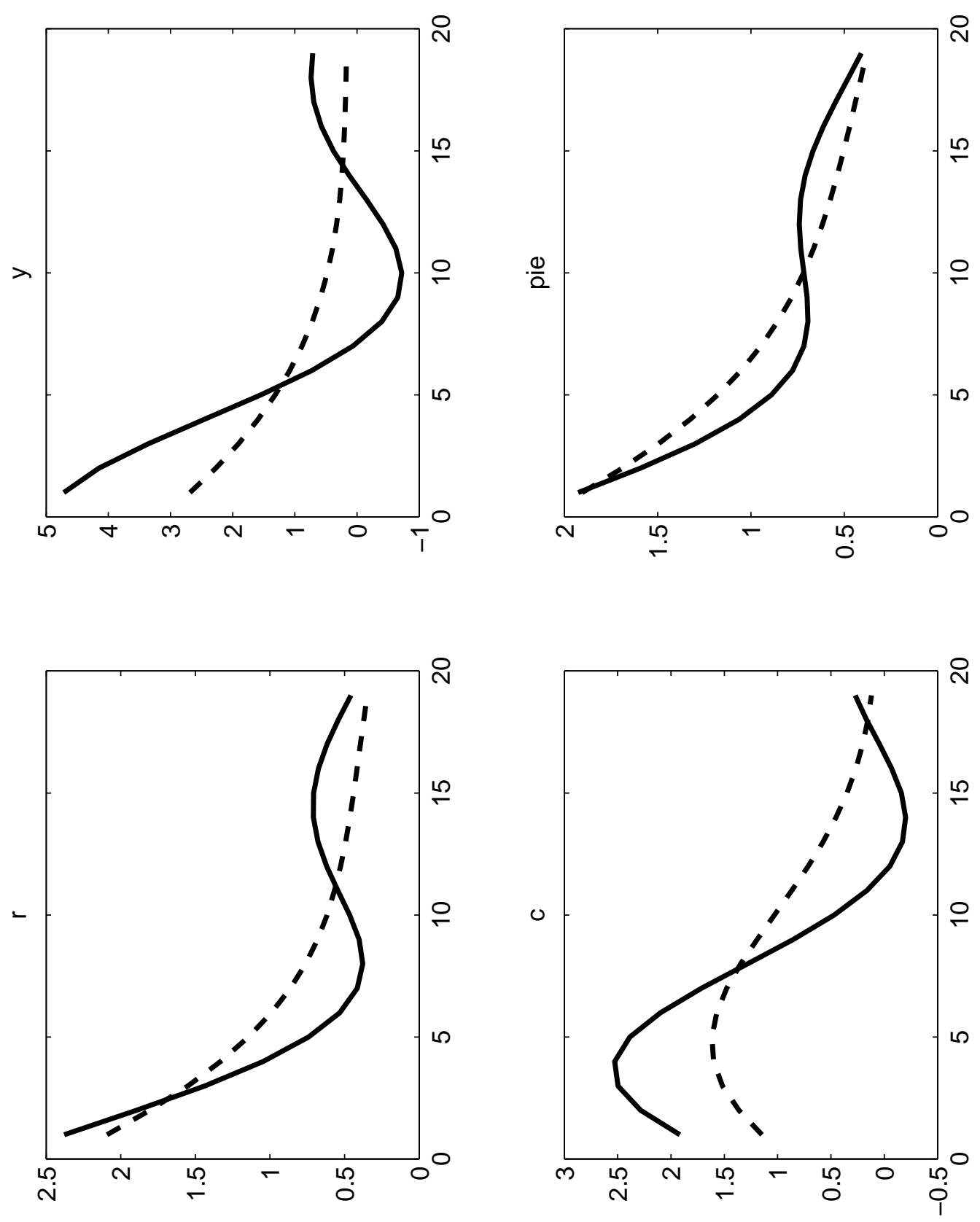

Figure 11: Simulated monetary policy IRF (\% dev SS) baseline model (solid line) and the counterfactual no-liquidity effect scenario (dashed line) 

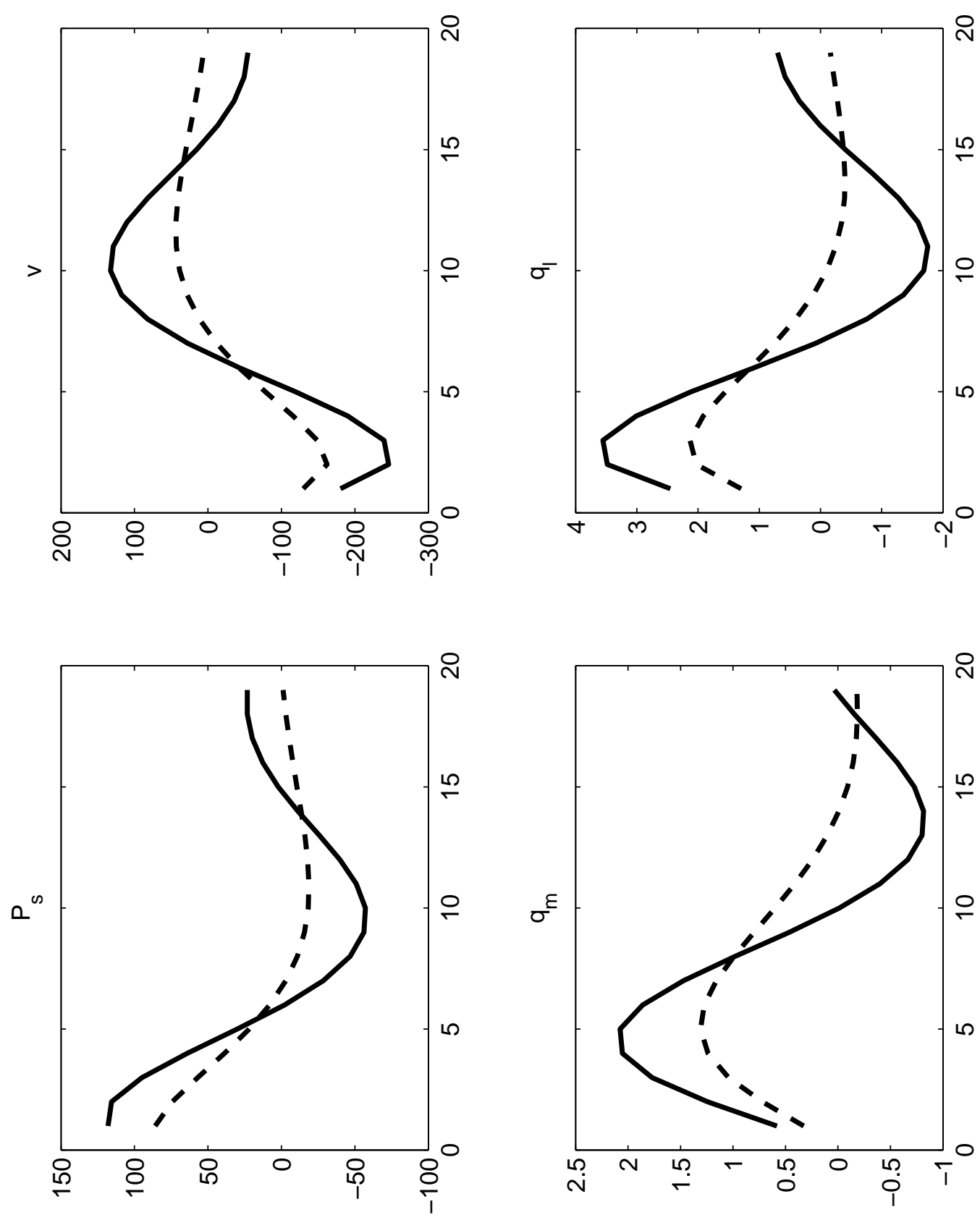

Figure 12: Simulated housing subsidy policy IRF (\% dev SS) baseline model (solid line) and the counterfactual no-liquidity effect scenario (dashed line) 

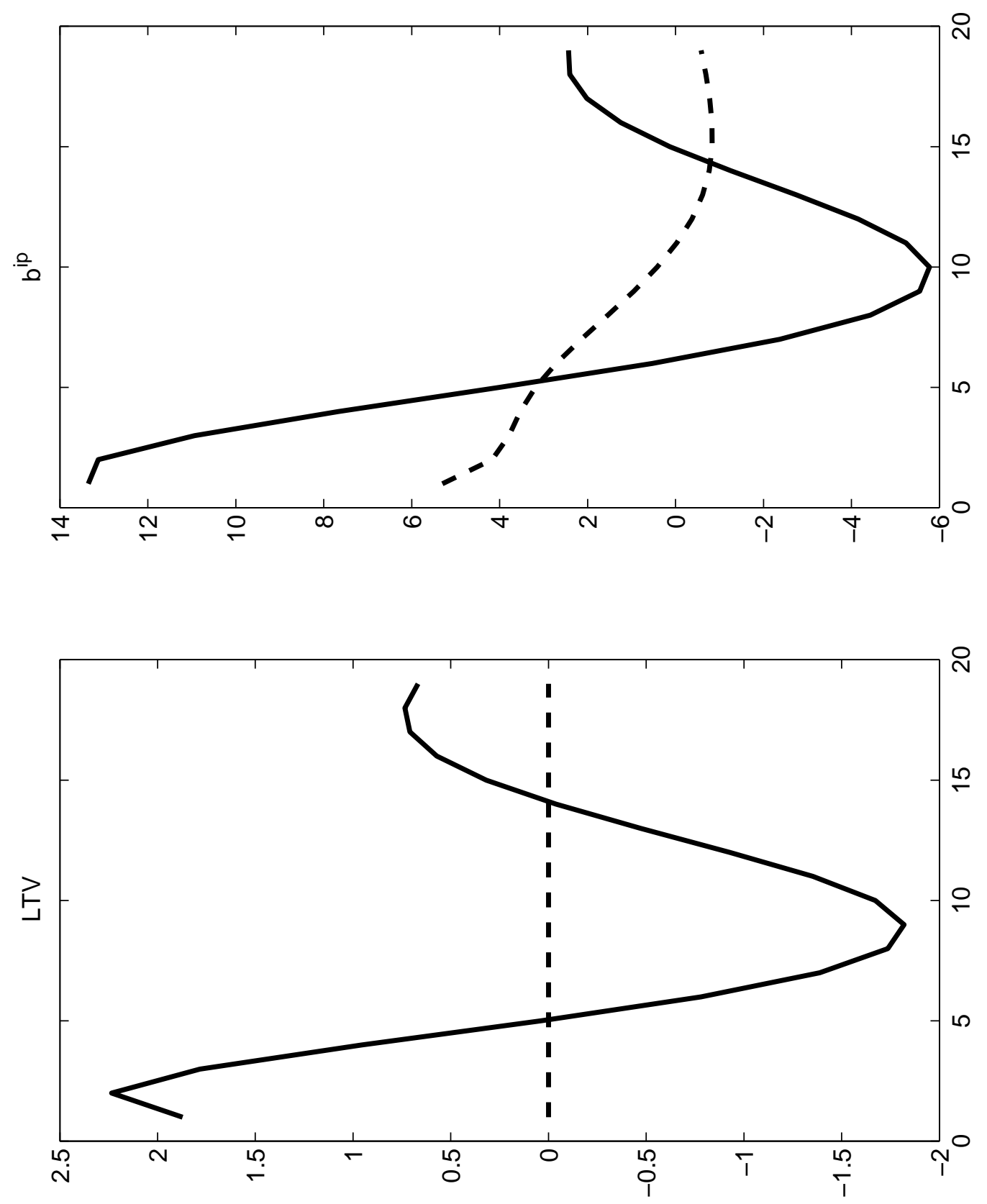

Figure 13: Simulated housing subsidy policy IRF (\% dev SS) baseline model (solid line) and the counterfactual no-liquidity effect scenario (dashed line) 

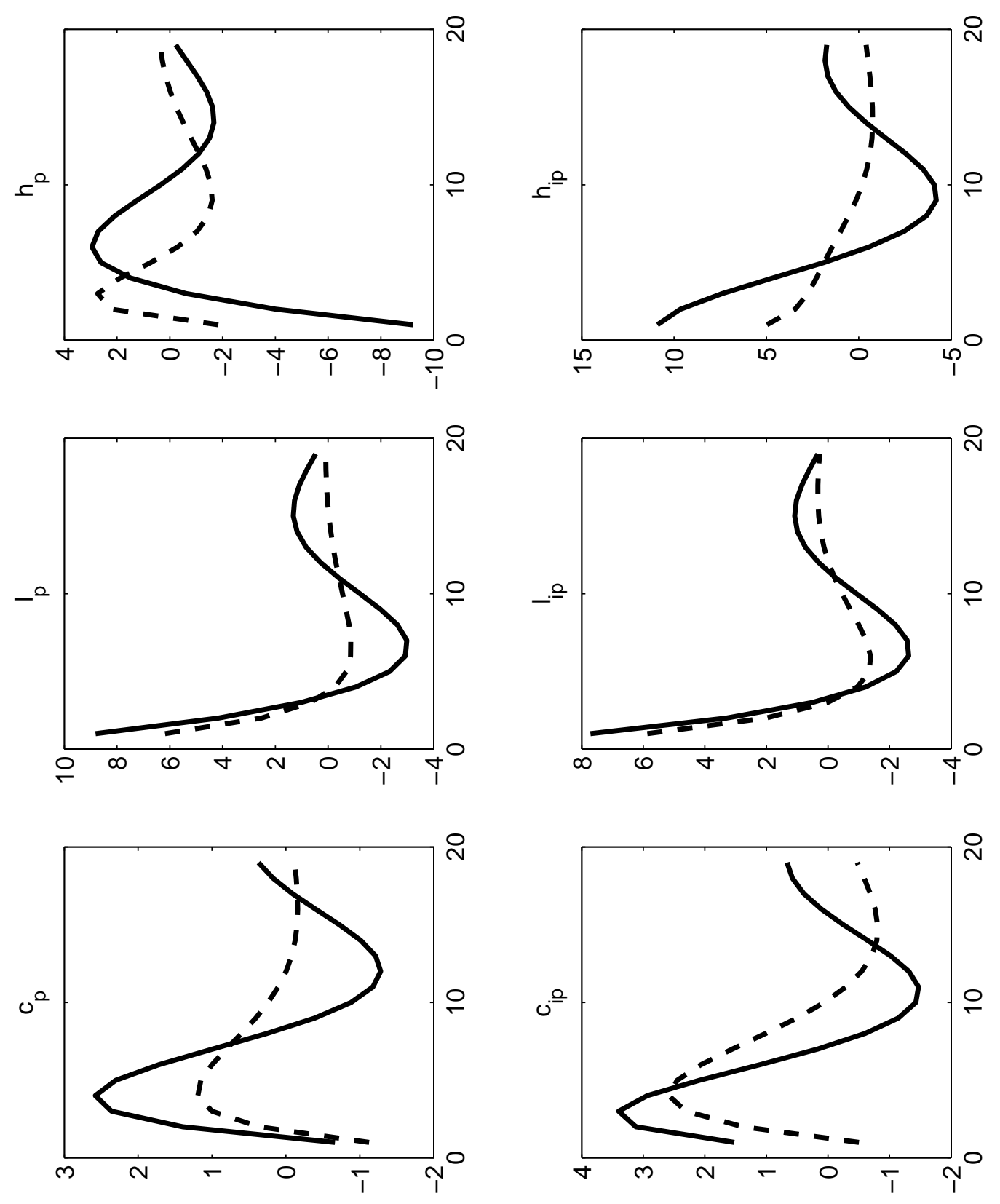

Figure 14: Simulated housing subsidy policy IRF (\% dev SS) baseline model (solid line) and the counterfactual no-liquidity effect scenario (dashed line) 

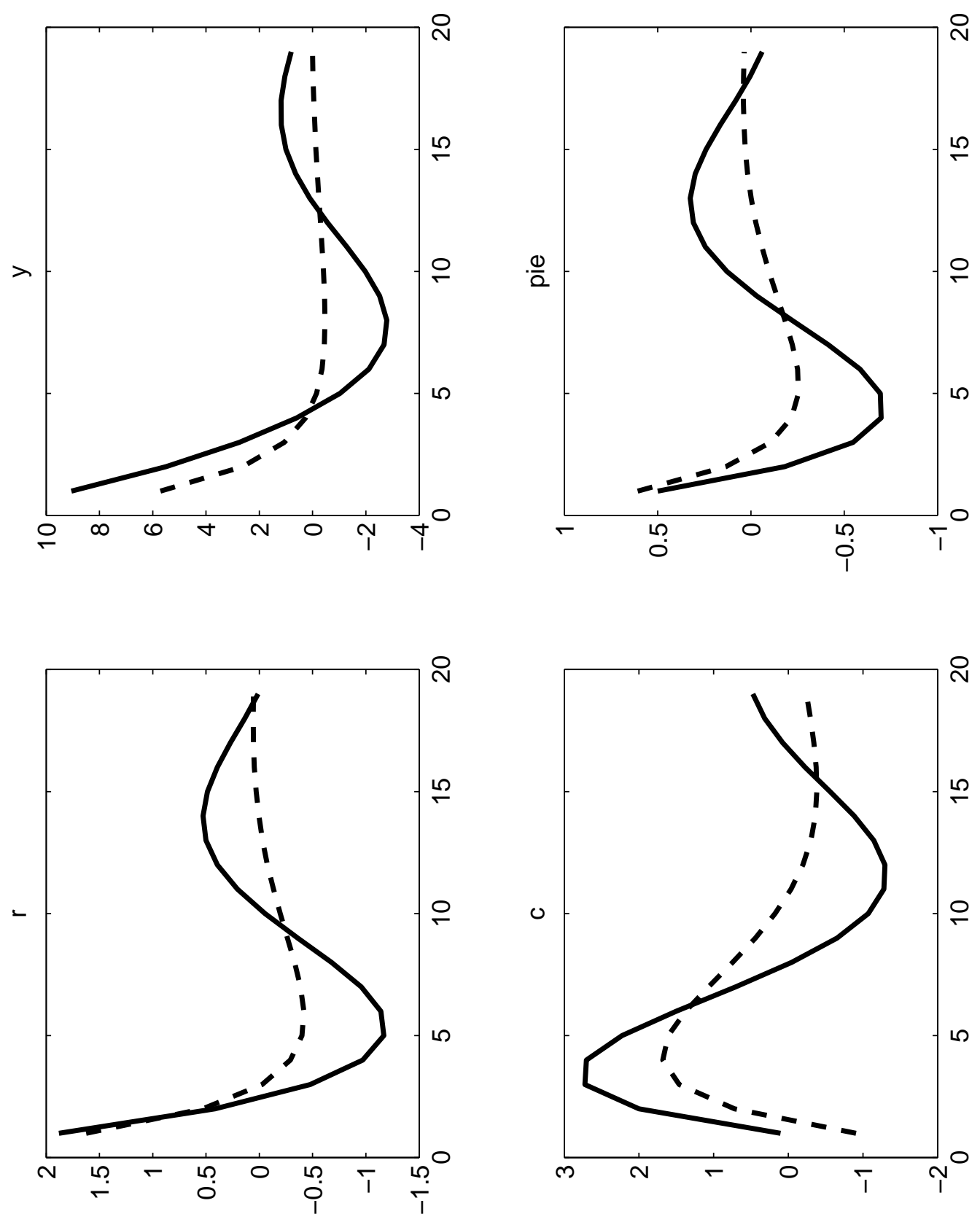

Figure 15: Simulated housing subsidy policy IRF (\% dev SS) baseline model (solid line) and the counterfactual no-liquidity effect scenario (dashed line) 

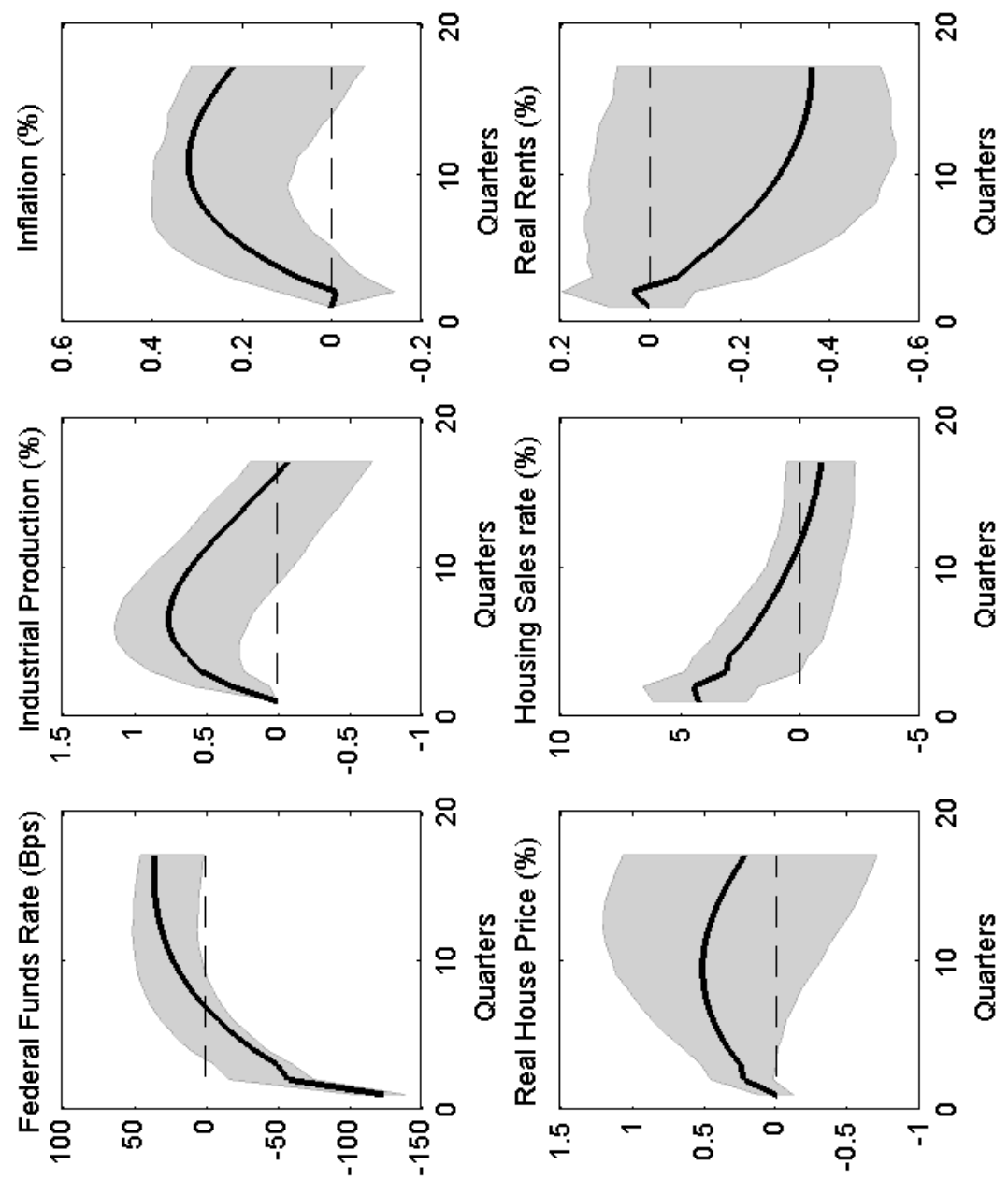

Figure 16: Response of the housing market (Recursive identification VAR; in log dev. from trend; $95 \%$ confidence intervals) 

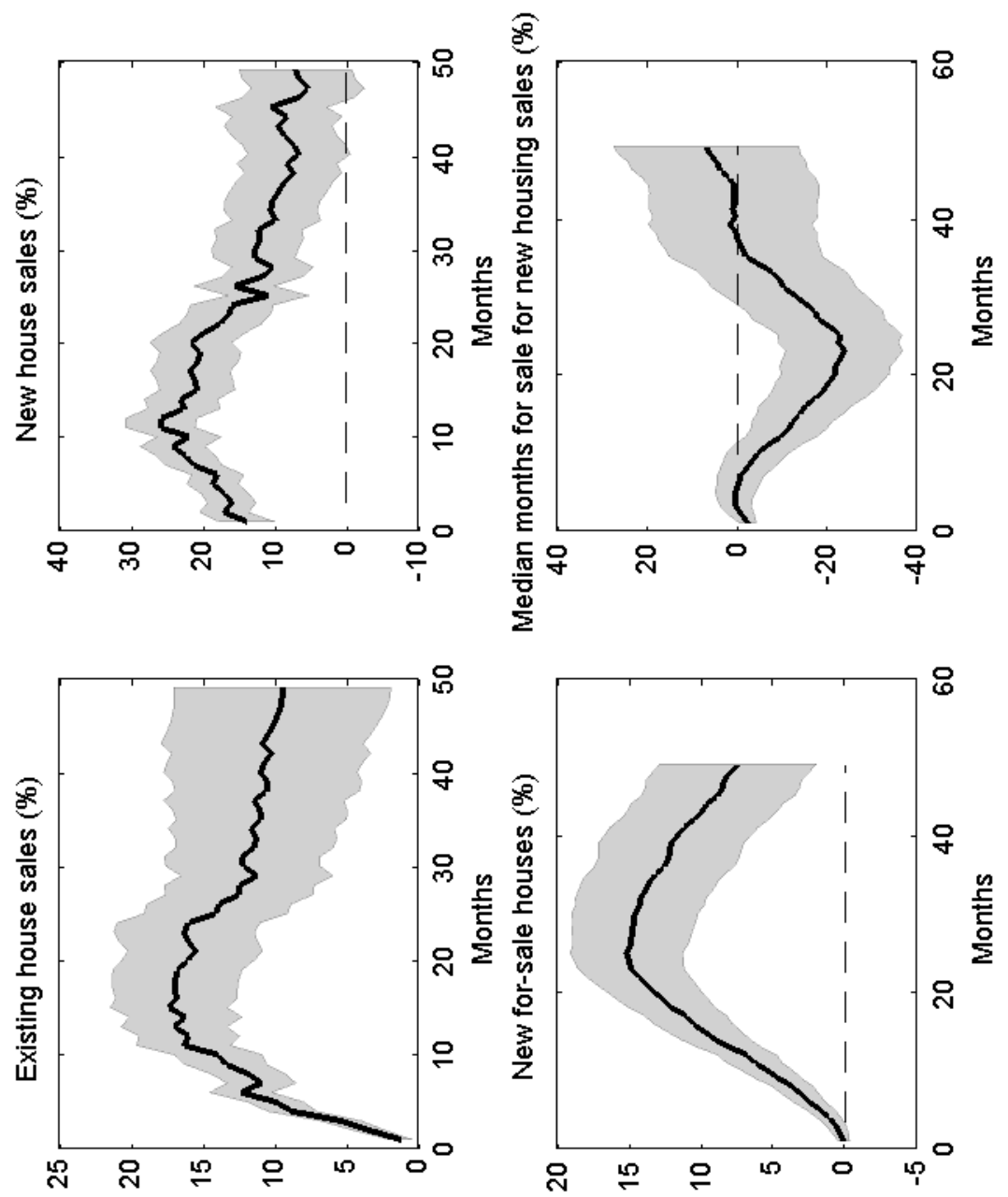

Figure 17: Response of other housing liquidity measures (Romer and Romer (2004) shocks; in log dev. from trend; $95 \%$ confidence intervals) 
Consumer preferences

\begin{tabular}{lcc}
\hline$\beta_{p}$ & $0.99^{\frac{1}{4}}$ & Iacoviello \& Neri (10) \\
$\beta_{i p}$ & $0.97^{\frac{1}{4}}$ & Iacoviello \& Neri $(10)$ \\
$\chi_{h}$ & 0.25 & $\frac{q_{m}^{*} h^{*}}{y^{*}}=6$ (Iacoviello (05)) \\
$\chi_{l}$ & 1 & Iacoviello (05) \\
$\varphi$ & 1 & elastic labour demand
\end{tabular}

Production technology

\begin{tabular}{lcc}
\hline$\alpha$ & 0.3 & Labour income share of $70 \%$ \\
$\vartheta_{f}$ & 0.75 & av. 1 yr price reset (Iacoviello $(05))$ \\
$\lambda_{f}$ & 1.15 & Iacoviello $(05)$ \\
$\mu$ & 0.5 & Sterk $(2010)$ \\
& & \\
Housing search market & & \\
\hline$z$ & 0.0278 & av. ownership 9 yrs (Ngai \& Tenreyro $(09))$ \\
$\kappa_{b}$ & 1.57 & satisfy buyer free entry \\
$F_{s}$ & 0.1 & $V_{s}^{*}$ \\
$F_{m}^{*}$ & 0.85 (emp. fire-sale discount) \\
$\frac{m}{q_{m}^{*}}$ & 0.1 & $F_{b}=F_{s}$ \\
$\frac{\tau}{q_{m}^{*}}$ & $0.04 / 4$ & Poterba $(91)$ \\
$\omega$ & $0.02 / 4$ & Poterba $(91)$ \\
$\gamma$ & 0.19 & match housing market impulse response \\
$s$ & 0.1 & match housing market impulse response
\end{tabular}

\begin{tabular}{lcc} 
Policy & & \\
\hline$r_{y}$ & 0.21 & Iacoviello $(05)$ \\
$r_{\pi}$ & 0.16 & Iacoviello (05) \\
$r_{r}$ & 0.72 & Iacoviello (05) \\
$\tau_{h}$ & 0.5 & split housing return evenly across types \\
$\rho_{m}$ & 0.8 & match housing market impulse response \\
$\epsilon_{1, m}$ & 0.007 & match housing market impulse response
\end{tabular}

Table 1: Calibration for baseline DSGE 
Federal funds rate

Output

Price level

House prices

Rents

New housing sales rate

Sales volume (existing housing)

Sales volume (new housing)

Sales volume (existing housing)

For-sale housing (new housing)

Med. for-sale months (new housing)
Federal Reserve Board (FRB) H.15

Ind. prod. (major ind. groups) (FRB) G.17

Bureau of Labour Statistics (BLS) CPI

Freddie Mac House Price Index (FMHPI)

Bureau of Labour Statistics (BLS) CPI

US Census new residential housing

National Association of Realtors

US Census new residential housing

National Association of Realtors

US Census new residential housing

US Census new residential housing

Table 2: Data sources 